University of Louisville

ThinkIR: The University of Louisville's Institutional Repository

$5-2014$

\title{
Applications of GIS analyses and ecological approaches to paleolithic sites in Portugal.
}

Christopher M. Sims

University of Louisville

Follow this and additional works at: https://ir.library.louisville.edu/etd

Part of the Anthropology Commons

\section{Recommended Citation}

Sims, Christopher M., "Applications of GIS analyses and ecological approaches to paleolithic sites in Portugal." (2014). Electronic Theses and Dissertations. Paper 1329.

https://doi.org/10.18297/etd/1329

This Master's Thesis is brought to you for free and open access by ThinkIR: The University of Louisville's Institutional Repository. It has been accepted for inclusion in Electronic Theses and Dissertations by an authorized administrator of ThinkIR: The University of Louisville's Institutional Repository. This title appears here courtesy of the author, who has retained all other copyrights. For more information, please contact thinkir@louisville.edu. 


\title{
APPLICATIONS OF GIS ANALYSES AND ECOLOGICAL APPROACHES TO PALEOLITHIC SITES IN PORTUGAL
}

\author{
By \\ Christopher M. Sims \\ B.A., Appalachian State University, 2008 \\ M.A., University of Louisville, 2014 \\ A Thesis \\ Submitted to the Faculty of the \\ College of Arts and Sciences of the University of Louisville \\ in Partial Fulfillment of the Requirements \\ for the Degree of \\ Master of Arts \\ Department of Anthropology \\ University of Louisville \\ Louisville, Kentucky
}

May 2014 



\title{
APPLICATIONS OF GIS ANALYSES AND ECOLOGICAL APPROACHES TO PALEOLITHIC SITES IN PORTUGAL
}

\author{
By \\ Christopher M. Sims \\ B.A., Appalachian State University, 2008 \\ M.A., University of Louisville, 2014 \\ A Thesis Approved on
}

April 30, 2014

By the following Thesis Committee:

Thesis Director

Dr. Jonathan Haws, University of Louisville Department of Anthropology

Mr. Philip Diblasi, University of Louisville Department of Anthropology

Mr. Robert Forbes, University of Louisville Department of Geosciences 


\section{ACKNOWLEDGMENTS}

I would like to thank Dr. Jonathan Haws, Mr. Philip Diblasi, and Mr. Robert Forbes at the University of Louisville, as well as Dr. Mike Benedetti at the University of North Carolina-Wilmington for their assistance, direction, and mentorship in this thesis; Dr. Fabian Crespo and Dr. Justin Mog for their leadership and guidance - both professionally and academically; Ms. Shelly Biesel and Mr. Dave Schatz for their solidarity and support as colleagues and friends; Ms. Andee Zorn for her love, inspiration, and motivation (and supernatural ability to mediate my stress levels); my family - John, Kristen, Jonathan, and Kayla - for their boundless love and unwavering encouragement throughout my journeys as an archaeologist.

I would also like to acknowledge "Death Squad", the archaeology survey team that set me on the path of no return in our trials, adventures, and successes as field archaeologists.

Sempre en frente 


\title{
ABSTRACT: \\ APPLICATIONS OF GIS ANALYSES AND ECOLOGICAL APPROACHES TO PALEOLITHIC SITES IN PORTUGAL
}

\author{
Christopher Sims
}

April 30, 2014

Developments in landscape approaches to archaeological research have been greatly advanced by the use of geospatial technologies. Despite this boon, certain questions remain where the spatial distributions of archaeological material are complicated by other factors. Geomorphic processes significantly hinder site survivability and visibility, and complicate fieldwork. Such is the case for Paleolithic archaeological sites in Portugal, where the current landscape has been drastically altered since Paleolithic human occupation at the Last Glacial Maximum. The challenge to landscape-scale approaches is to provide a bridge between long-term environmental factors and smaller-scale evidence for human-ecosystem interaction. This requires that adaptations be made to landscape approaches and applications of geospatial technology, and adjustments to conceptual frameworks regarding site distribution are necessary in order to understand locality patterns. This work focuses on the results of geospatial analysis of data from recent archaeological investigations of the Paleolithic in the coastal region of Estremadura in Portugal, and places them within conceptual frameworks that account for severe environmental changes and limited site survivability. 


\section{TABLE OF CONTENTS}

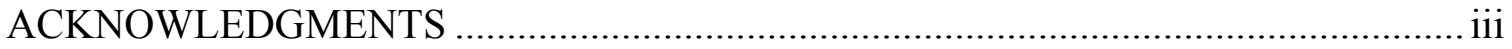

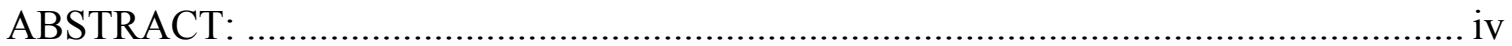

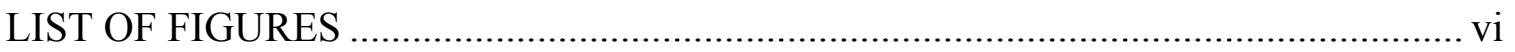

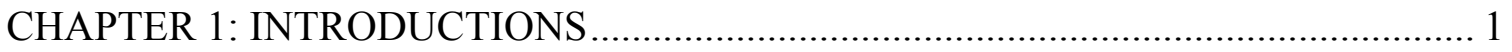

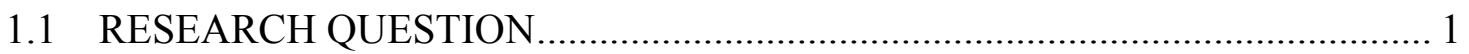

1.29

INTRODUCTION TO APPLICATION OF LANDSCAPE APPROACHES IN

UNDERSTANDING ARCHAEOLOGICAL DISTRIBUTIONS. ............................. 9

1.312

INTRODUCTION TO THE USE OF GIS IN THIS RESEARCH............................ 12

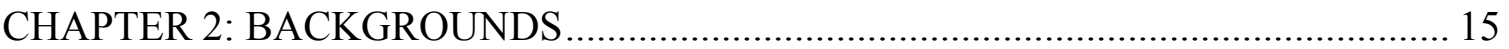

2.1 DEVELOPMENT OF GIS IN ARCHAEOLOGY........................................... 15

2.2 BACKGROUND AND APPLICATIONS OF LANDSCAPE APPROACHES IN

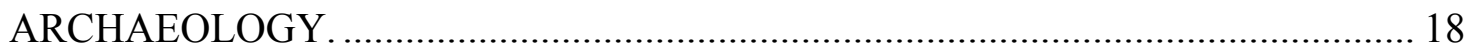

2.3 ARCHAEOLOGICAL CONTEXTS IN PORTUGAL: COASTAL AND

INLAND SITES, AND PREVIOUS WORK RELATING TO THIS RESEARCH. ... 34

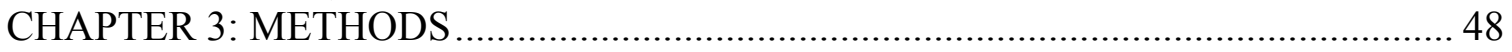

3.1 ARCHAEOLOGICAL SURVEY METHODS ….......................................... 48

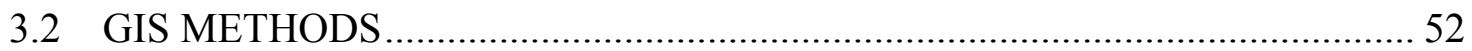

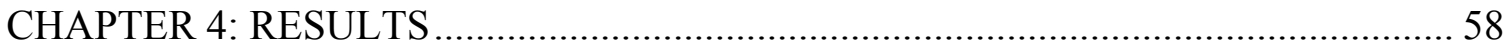

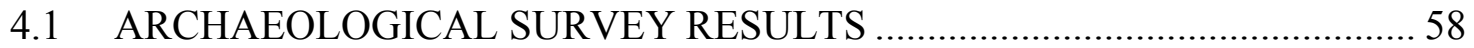

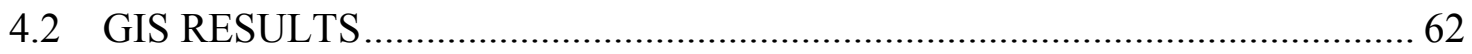

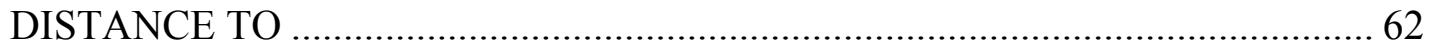

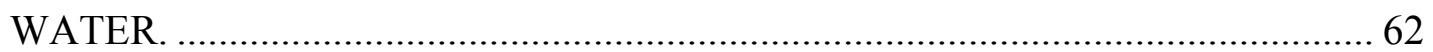

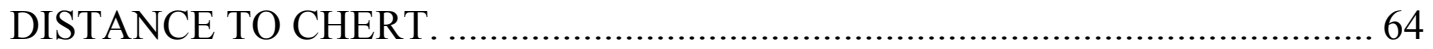

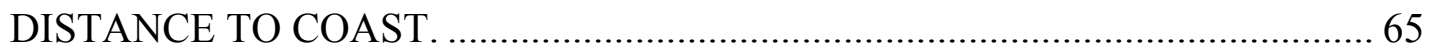

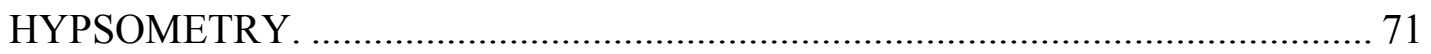

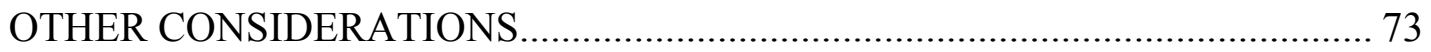

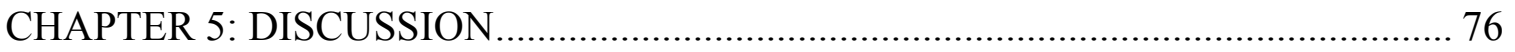

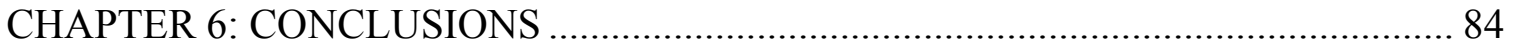

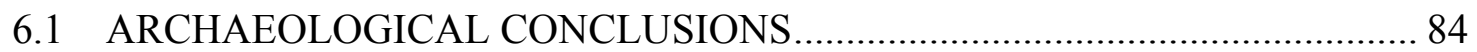

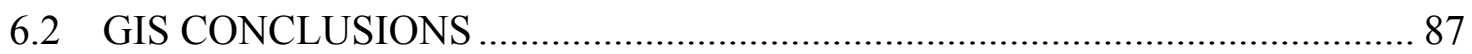

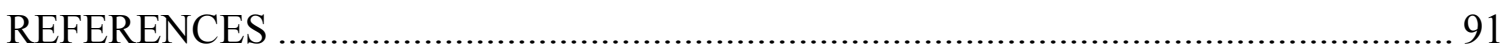

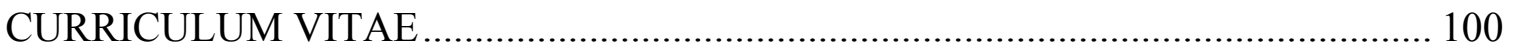




\section{LIST OF FIGURES}

Figure 1.1 Overview of coastal contexts at Paleolithic site, Vale Pardo, facing northwest.

Figure 1.3 Location of study area in Portuguese Estremadura, showing Paleolithic

localities

Figure 2.1 The Adaptive Cycle Model (Redman 1999). ............................................... 22

Figure 4.1 Paleolithic Sites in Portuguese Estremadura ................................................. 59

Figure 4.2 Location of Paleolithic Sites in Relation to Water ....................................... 62 Figure 4.3 Proximity of Paleolithic sites in relation to known chert sources, showing $5 \mathrm{~km}$

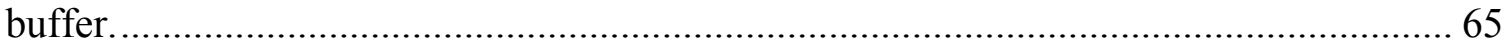

Figure 4.4 Distance from Paleolithic Localities to Marine Coast................................... 67 Figure 4.5 Insolation values for coastal research area, showing location of Paleolithic

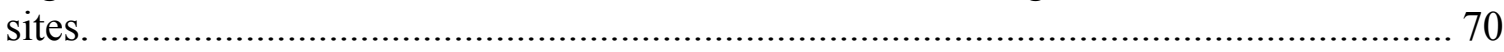
Figure 4.6 Hypsometric values for coastal research area, showing Paleolithic localities. 73 Figure 6.1 Overview of Middle Paleolithic site, Lagoa Seca, facing northwest. ............ 85 


\section{CHAPTER 1: INTRODUCTIONS}

\subsection{RESEARCH QUESTION}

This thesis uses geospatial technology to highlight the importance of understanding human decision-making in the past. The research here presents the results from Geospatial Information System (GIS) analyses of archaeological surveys conducted by the ASEM project directed by Jonathan Haws (University of Louisville) and Michael Benedetti (University of North Carolina Wilmington). This project, in which I participated over the past two years (2012 and 2013), is an ongoing geoarchaeological survey for Paleolithic sites in Central Portugal. The primary goal of the ongoing project is to understand human response to environmental change during the Late Pleistocene. Here, I use GIS to determine the location of Paleolithic sites in relation to a set of environmental variables. I then synthesize the results within a conceptual framework outlined by landscape approaches to human behavior.

Following Maxwell (1996), this work developed a concept map to illustrate the structure of this research. This figure is designed to provide simple links between the concepts applied in this thesis. Conceptual models describing broad-spectrum revolution, coastal-inland movement, and resource distribution, as well as the factor of solar 
insolation link the two main concepts of regional site distribution and evidence for human behavior. These concepts are considered in this research as the links between spatial organization in the Estremadura, and finer-grained trends of human behavior from more localized investigations (Haws et al. 2010; Haws 2012; Shokler 2002; Thacker 1996). More details on the impacts to archaeological site distribution and evidence for human decision-making are presented throughout this thesis.

The main purpose of this research is to present an effective analysis of Paleolithic settlement and subsistence on a landscape scale. This will be accomplished through constructing a theoretical consideration for hunter-gatherer responses to ecosystem pressures and severe climate change. This involves the study of several complex, interconnected processes on many different levels of action.

The research question investigated in this thesis is best asked: does the regional-scale distribution of archaeological material accurately reflect characteristics observed within site-level investigations? Trends in Paleolithic human settlement and subsistence patterns, evident in the archaeological record, show responses to pressures from the environment and human populations (Bicho and Haws 2008; Cascalheira and Bicho 2013; Haws et al. 2010; Shokler 2002; Thacker 1996). Geomorphological data, proxy climate data, and cultural material assemblages recovered at site-level archaeological investigations offer potential to view diachronic factors impacting human behavior. Changes to the environment and to human behavioral patterns, seen over time, are important in understanding the broader shifts in environmental and human contexts. This highlights the usefulness of a broader scale of approach in order to link trends throughout the Estremadura during the Paleolithic - something that can perhaps best be accomplished 
through spatial analysis. In other words, can GIS and landscape approaches confirm explanations proposed by researchers for drastic changes that occurred during the Upper Paleolithic in Portugal? Noticeable overlaps are present in the conceptual frameworks guiding landscape-scale approaches to archaeology, and in the application of GIS to the Paleolithic in Estremadura. An evolutionary ecological perspective guides much of the archaeological background presented in the following chapters, as well as the application of GIS to Paleolithic localities and subsequent interpretations.

Archaeological surveys in Central Portugal conducted by the ASEM project (Haws et al. 2010; Haws 2012) yielded lithic scatters in degraded contexts, and recent excavations of productive surface deposits resulted in a puzzling lack of subsurface material. The immediate impression given from these field observations was one of a troublesome archaeological record that has been greatly impacted by post-depositional forces, drastic climate change, and millennia of landscape-altering land-use practices. Despite these impacts to the regional distribution of archaeological material, there still remains potential to further our understanding of Paleolithic settlement and subsistence. The spatial distribution of archaeological sites is very reliant upon environmental contexts, which are also significantly impacted by post-depositional processes (Benedetti et al. 2009; Cohen et al. 2008; Fanning et al. 2009; Holdaway and Fanning 2008). Other factors that influence site distribution and integrity come into play as well. The behavior leading to the deposition of archaeological material is central to archaeology as a discipline (Schiffer and Skibo 2008), as is the survivability and detection of archaeological material (Hodder and Orton 1976). Archaeologists have known for decades that Pleistocene humans exploited coastal environments including shorelines, 
intertidal zones, and near-coastal areas (Bicho and Haws 2008; Cascalheira and Bicho 2013; Erlandson 2001; Haws et al. 2010; Haws 2012). However, the scale and intensity of coastal settlement remains poorly understood. Site distribution and survivability have presumably been altered due to the inundation and destruction of coastal margins at the end of the Last Glacial Maximum (Benedetti et al. 2009; Cascalheira and Bicho 2013; Garcia 2013). Although the melting of continental ice sheets resulted in a rise in mean sea level, the steep near-shore bathymetry and complex tectonic forces of coastal Portugal have acted to preserve Paleolithic coastal sites (Benedetti et al. 209; Garcia 2013). While uplift did spare some sites from marine transgression, it also acted to expose them to terrestrial erosional forces that have significantly impacted site survival and integrity (Benedetti et al. 2009; Burke et al. 2011). These combined processes have significantly limited coastal site visibility and created some serious challenges to our understanding of Pleistocene coastal settlement. Figures 1.1 and 1.2 present coastal uplift conditions at the Paleolithic site of Vale Pardo. 


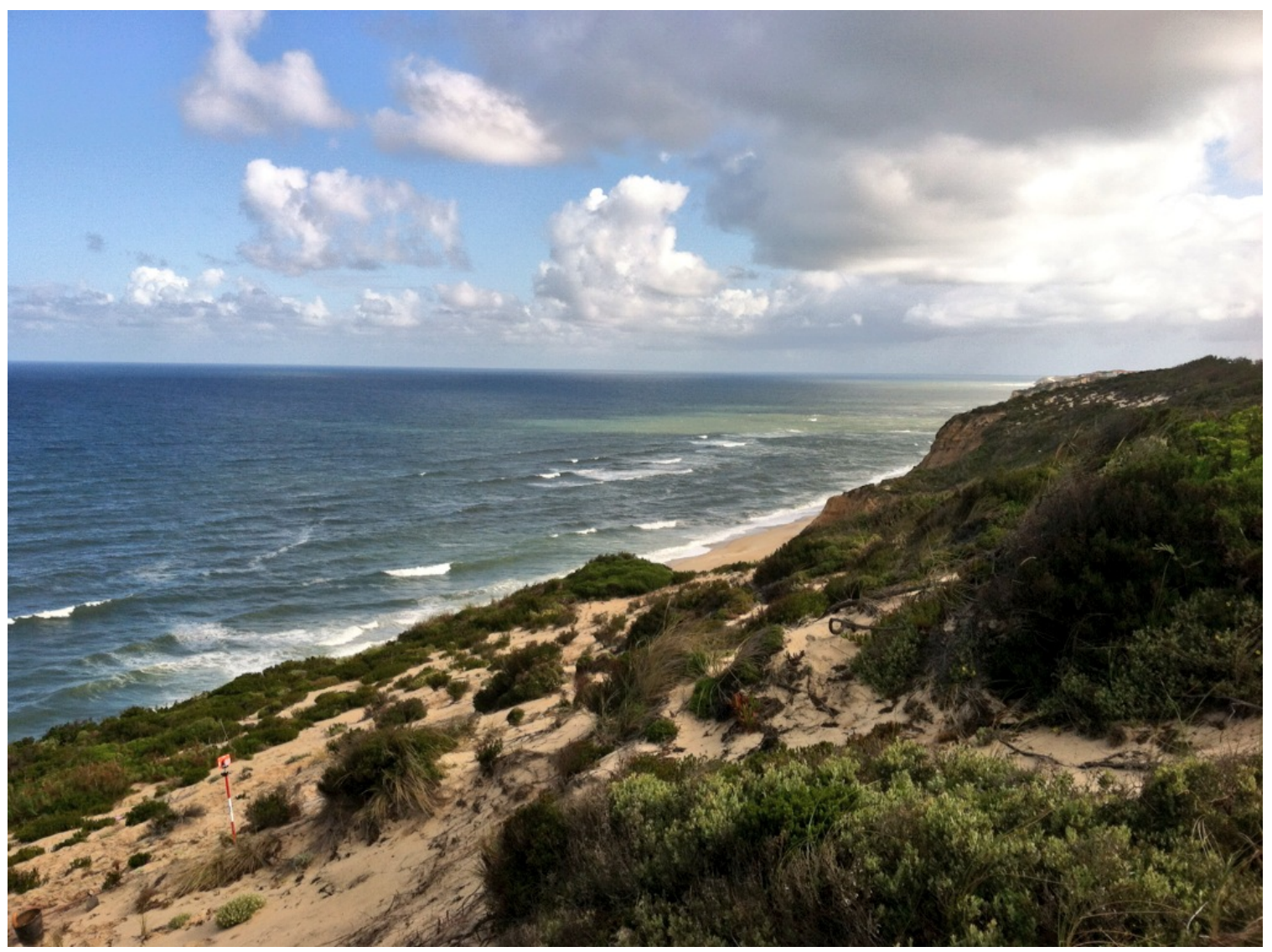

Figure 1.1 Overview of coastal contexts at Paleolithic site, Vale Pardo, facing northwest. 


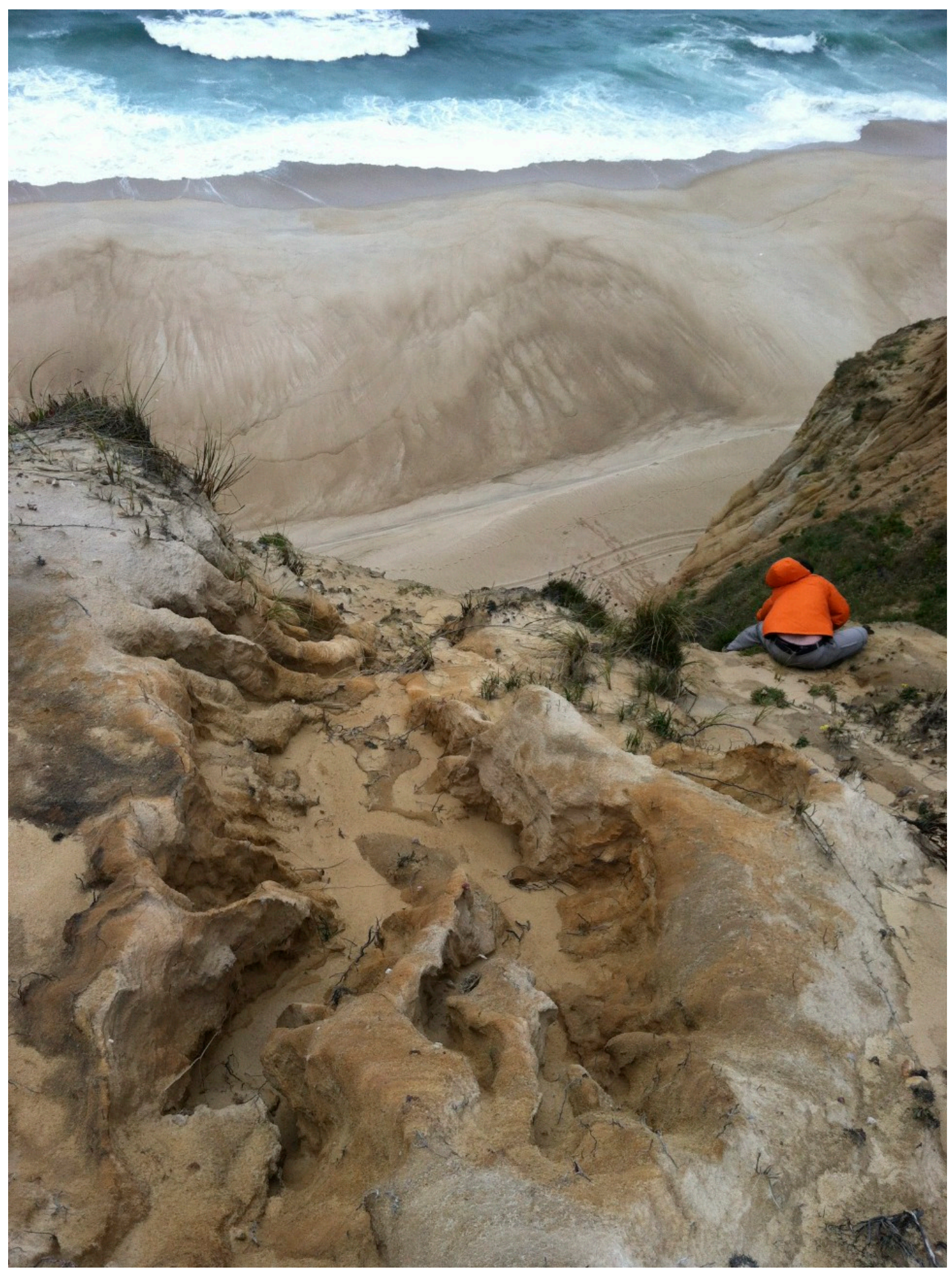

Figure 1.2 Overview of deflated sediments near Paleolithic surface scatters in association with Vale Pardo site,

facing west. 
The spatial scope of this study encompasses an area in the Estremadura region of Central Portugal that includes coastal and inland sites extending approximately 20 kilometers inland from the current shoreline (figure 1.2). The study area is bounded to the north by the modern town of São Pedro de Moel; to the east by Serra Candeeiros, an uplifted limestone massif; to the south by the modern coastal town of Peniche and the limestone escarpment near the historic town of Óbidos; and to the west by the Atlantic Ocean. This region was chosen because its proximity to both coastal and terrestrial resources, and the unique patchiness of ecosystems in this terrain pose interesting potentials to view adaptive behavior. Recent research argues for the importance of Estremadura as a refugium for the late survival of Neanderthal populations during the Middle Paleolithic, and for phases of cultural succession throughout the Upper Paleolithic (Bicho and Haws 2008; Haws et al. 2010; Haws 2012). Indeed, Barton et al.(2013:53) emphasize the importance of Portugal during the Paleolithic as representing "the largest region of Europe beyond glacial terrains [during the late Pleistocene].”.

The archaeological and environmental contexts for this research include greater Portugal and Iberia, however the rest of Western Europe is deliberately excluded due to significant differences in cultural and environmental characteristics. Given the scale of data for long-term environmental changes operating at scales of thousands or tens of thousands of years (Benedetti et al. 2009; Cascalheira and Bicho 2013; Garcia 2013), the scale of time must often be opened to include broader factors during the Paleolithic. At times this study refers to the Paleolithic in a general sense to describe hunter-gatherer strategies during the Late Pleistocene, however, Middle and Upper Paleolithic (i.e. Gravettian, Proto-Solutrean, Solutrean, Magdelenian) are directly described when 
discussing specific details for each cultural phase (Bicho and Haws 2008; Cascalheira and Bicho 2013; Haws et al. 2010; Haws 2012). This often-broad level of discussion is the result of considerable difficulty in establishing a clear chronological succession of technological and cultural complexes in Portugal during the Paleolithic (Cascalheira and Bicho 2013). The unique characteristics of terrain, environment, and human populations make Portugal an important area of study for this time period.

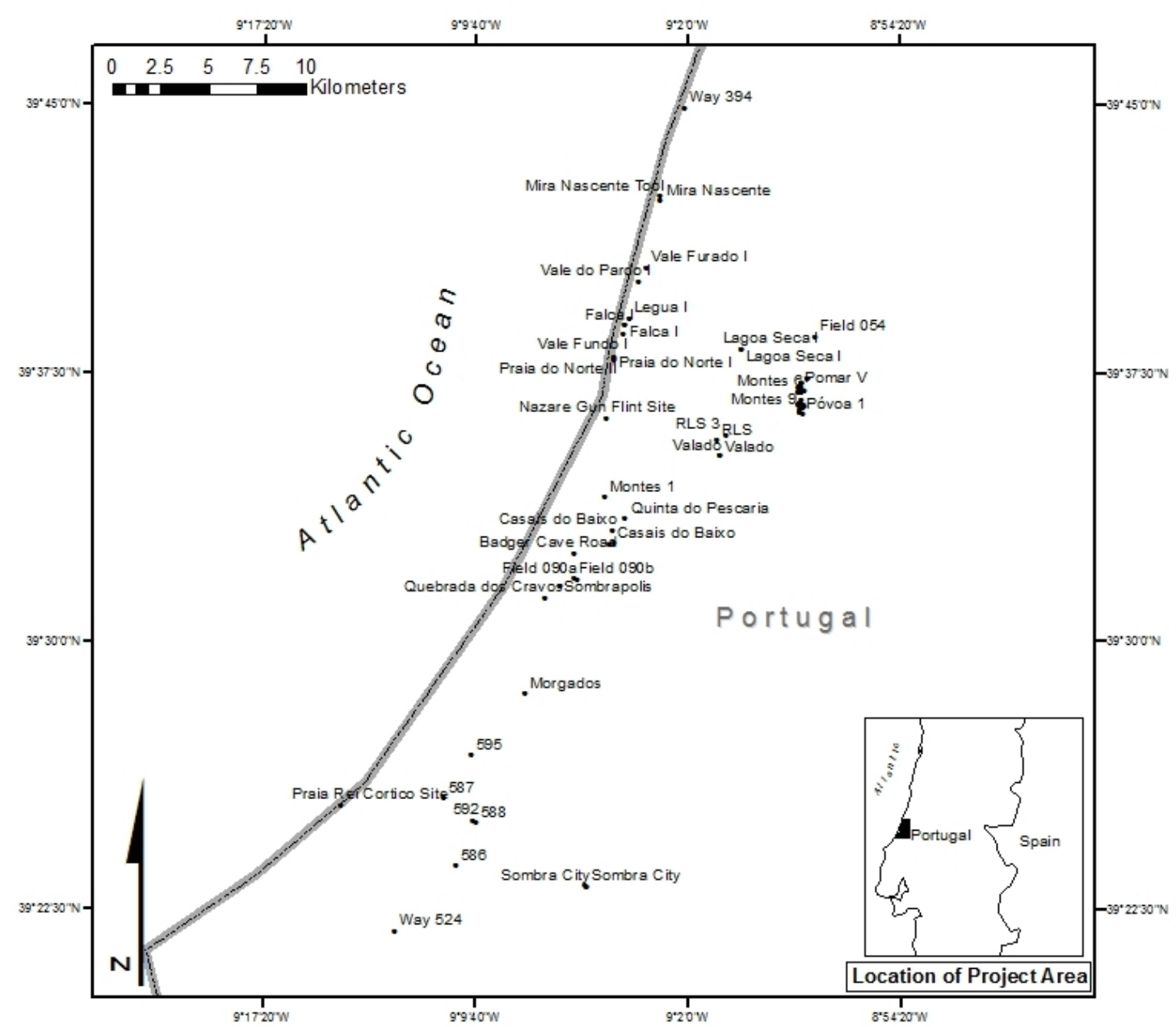

Figure 1.3 Location of study area in Portuguese Estremadura, showing Paleolithic localities. 
This thesis is organized into seven main chapters, each subdivided into distinct sections. This first chapter introduces the subject of this research, and briefly outlines the key concepts and contributions underpinning this research design, methods and interpretations. The second chapter provides more detailed backgrounds to the basis for this thesis, with sections divided to cover the development of GIS in archaeology, applications of landscape-scale studies and human behavioral ecology, and a description of archaeological contexts in Portugal that form the background of previous work relating to this research. Chapter three presents the archaeological survey and data collection methods, and the GIS methods that are employed in analyzing archaeological data. The results of this GIS analysis are presented in chapter four, with subsequent discussions on the interpretation of this data following in chapter five. Finally, chapter six offers conclusions for the implications of this research.

\subsection{INTRODUCTION TO APPLICATION OF LANDSCAPE APPROACHES IN UNDERSTANDING ARCHAEOLOGICAL DISTRIBUTIONS.}

Landscape approaches to human-environment interactions are featured prominently in discussions and interpretations throughout this thesis. A far more thorough background on this perspective is offered in the following chapter, but for the purposes of an introduction I will briefly discuss the significance of landscape approaches here. This interdisciplinary school of thought has seen ever-greater prominence in archaeology in the past couple decades (Redman 1999; Van der Leeuw and Redman 2002; Van der Leeuw et al. 2004). The theoretical perspectives used in landscape approaches broadly refer to a collection of ecological and behavioral models that account for the net effect of 
human interaction with the environment (Redman 1999). This conceptual framework has been particularly productive in archaeological applications because it adds a human element to complex environmental processes. As Redman explains, "humanenvironmental relations cannot be modeled in a strictly mechanistic way on some maximization theory; one must account for the "human" factor" (1999: 7). Additionally, Redman (1999) outlines the conceptual groundwork that landscape approaches have contributed (in particular regard to prehistoric hunter-gatherer societies). Firstly a landscape approach dispels the natural fallacy that has traditionally plagued huntergatherer studies, in which a natural landscape exists, "untouched by human hands... and that societies before [modern] European contact lived in a utopian paradise guided by an unselfish conservation ethic" (Redman 1999: 13). The focus on human impact on ecosystems becomes increasingly dominant the deeper one looks into landscape approaches. Secondly, and this is incredibly relevant to this thesis, "human impacts in antiquity, not just climactic changes (my italics), have led to significant environmental alterations" (Redman 1999: 13). This argument has shaped the application of conceptual models in this research by avoiding environmental determinism in interpreting humanecosystem interaction in Paleolithic Estremadura (Bicho and Haws 2008; Haws 2012). Third, discussions of climate and the interaction of organisms and their physical surroundings tends to avoid human involvement, and landscape approaches mark a clear departure from this mode of thought by injecting models that can frame the complexity of human involvement in a system (Redman 1999). Fourth, Panarchy and resilience theory focus on the human decisions that either sustained settlement and subsistence, or that led to environmental degradation (Holling 2001; Redman 1999). While this is elaborated in 
the following chapter, it bears an immediate relevance to Paleolithic studies in Portugal by addressing the persistence or transience of cultural phases in the archaeological record (Bicho and Haws 2008; Bicho and Haws 2012; Burke et al. 2011).

Within the broader theoretical scope of landscape studies, the conceptual frameworks of Panarchy and resilience (Holling 2001; Holling and Gunderson 2002; Robbins 2004) provide useful models from which to study human-ecosystem interaction during the Paleolithic. The millennial scales of time at which climate oscillations occur throughout this period can best be related to cultural phenomena through Panarchical hierarchies (Holling 2001; Holling and Gunderson 2002). Haws (2012) couches his analysis of Paleolithic ecodynamics in the framework of Panarchy. The socionatural component of human behavior shows the potential for evolutionary models to further avoid environmental determinism by incorporating niche-construction theory - a model that accommodates human impact on ecosystems (Haws 2012). Niche construction is an important part of Paleolithic socionatural relationships (Haws 2012) that extends from the theoretical approaches of Panarchy and resilience (Holling 2001; Holling and Gunderson 2002). This accommodation of the human element in environmental change has been largely absent from human behavioral ecology, and presents a "passivity and invisibility of human agency inherent to many foraging models" (Haws 2012: 61). The inclusion of niche construction is further argued to offer "a more holistic and perhaps realistic approach to understand human impacts on past environments" (Haws 2012: 61). That study is but a point of entry for Panarchy; as other sections of this thesis explore Paleolithic human-ecosystem dynamics in Portugal, theoretical lines of discussion will remain close to the themes of Panarchy and resilience. 
Resilience is a topic that is often handmaiden to Panarchy, as it concerns the ecodynamics of a system that undergoes human interaction (Robbins 2004). Studies of the Paleolithic in Central Portugal have attempted to address resilience in hunter-gatherer interaction, to varying degrees of success (Bicho and Haws 2012; Cascalheira and Bicho 2013; Haws 2012).

While the concept of resilience is further elaborated upon in following parts of this thesis, it is important to note that, as with other conceptual models offered for Paleolithic human behavior in Portugal, much remains to be done before clearer pictures of humanecosystem interaction can be described. Concepts from Panarchy and resilience, as well as niche-construction, are incorporated in the human behavioral ecology perspective that is later discussed in this research.

\subsection{INTRODUCTION TO THE USE OF GIS IN THIS RESEARCH.}

The broad spatial-temporal parameters of large-scale changes over millennia are well suited to the powerful analytical potential of GIS. GIS can most simply be defined as computer systems that store, manipulate, analyze, and present spatial data (Wheatley and Gillings 2002). GIS is commonly used for computer-aided calculations providing measurements and mapping, as well as visual representations of spatial data and relationships. The four main components of a GIS include a data-entry subsystem, a spatial database, a manipulation and analysis subsystem, and a visualization and reporting subsystem (Wheatley and Gillings 2002). Broad definitions like this, Wheatley and Gillings argue, "are often so generic as to be almost meaningless" (2002: 9). Part of the difficulty in establishing a discrete definition for GIS is due to the diverse functionality of 
its use across many disciplines. Additionally, the graphic interfaces and tools available to GIS users are increasingly blending GIS, remote-sensing, database management, and computer-aided mapping and design (Wheatley and Gillings 2002). These powerful capabilities present attractive potential to the discipline of archaeology, especially in the ability to build explanations for spatial organization.

This study builds upon the recently growing field of geospatial analysis in archaeology. Geospatial associations have long been commonplace in archaeological investigations, however technological and methodological advances in the past two decades bear dramatic implications for GIS as a powerful tool in archaeological investigations (Conolly and Lake 2006; Howard 2007; Wheatley and Gillings 2002). GIS also offers ways to explain spatial relationships in adaptation to environmental conditions, territory and habitat choice, an in understanding "the result of a number of quasi-random post-depositional forces; the unplanned, accumulated and embedded product of everyday practice" (Wheatley and Gillings 2002: 16). In Portuguese Estremadura, the use of GIS shows potential to observe and quantify spatial relationships among Paleolithic sites and various landscape features. Archaeological applications of GIS on the Paleolithic in other areas of Iberia have been productive in strengthening explanations for changes in subsistence behavior related to climate change during the LGM (Burke et al. 2011; Garcia 2013). These studies investigate associations between sites and landscape features - namely distance to water and chert exposures, as well as solar insolation, and terrain characteristics.

I use the analytical models set forth by these GIS studies in determining the types of data to study Paleolithic Estremadura, but ultimately this analysis is limited by the 
availability of data and type of information recorded. For this reason, the following spatial-environmental relationships are expected to result from this data:

- Middle and Upper Paleolithic localities are expected to lay predominately within five kilometers of chert sources (Burke et al. 2011; Cascalheira and Bicho 2013).

- These sites or scatters are expected to be situated near water (Burke et al. 2011).

- Little archaeological context is expected to be identifiable for Upper Paleolithic cultural phases, perhaps simply due to low site counts suggested in previous research (Benedetti et al. 2009; Bicho and Haws 2008; Burke et al. 2011; Cascalheira and Bicho 2013; Garcia 2013). However this could account for factors such as: low or diminished populations, or even temporary localized extinctions (Cascalheira and Bicho 2013); emphasis of coastal resources toward the Upper Paleolithic being complicated by potential loss of shoreline (Benedetti et al. 2009; Burke et al. 2011; Garcia 2013; Haws et al. 2010); high degree of mobility among hunter-gatherer populations (Bicho and Haws 2008; Burke et al. 2011; Cascalheira and Bicho 2013; Haws et al. 2010); post-depositional site taphonomy and geomorphic processes (Benedetti et al. 2009; Burke et al. 2011; Fanning et al. 2009; Holdaway and Fanning 2008).

- Insolation is expected to play a factor in site location (Bicho et al. 2006; Garcia 2013).

I elaborate upon this further in the background and methods chapters. 


\section{CHAPTER 2: BACKGROUNDS}

\subsection{DEVELOPMENT OF GIS IN ARCHAEOLOGY.}

GIS continues to see a surge in popularity in archaeological applications (Wheatley and Gillings 2002). Many researchers throughout the discipline of archaeology at large work to promote the use of geospatial analyses in archaeology. As briefly mentioned in the preceding chapter, it is important to define what exactly a GIS is, and how it is used. A GIS, geospatial information system, is an integrated technological set of software and hardware requirements, geodetic and cartographic principles, and GIS data models (Connolly and Lake 2006). GIS is not only a powerful tool for archaeological research and graphic representation of data models, it is also a mode of explaining philosophical and theoretical frameworks for understanding and measuring human behavior in space. It is a difficult task indeed to provide a concise definition of a GIS, because a simple definition does little to show its functionality. The basic tasks of GIS can be broken into five main groups: data acquisition, spatial data management, database management, data visualization, and spatial analysis (Connolly and Lake 2006; Wheatley and Gillings 2002). The key strength of the use of GIS in archaeology is articulated by Connolly and Lake as, "the use of GIS has a much broader contribution to make in terms of understanding spatial and even space-time relationships between natural and 
anthropogenic phenomena" (2006: 11). In presenting data from a GIS, it is important to remember that the visualization of a digital model or map is an abstract representation of a sample from the physical world. Therefore, a great deal of energy and study must be invested in ensuring that the types of data and methods of GIS manipulation are consistent with the theoretical underpinnings that guide the larger research questions for which GIS analysis is conducted in the first place. Many researchers echo words of caution, that GIS cannot simply be 'tacked-on' and expect to yield any significant results (Connolly and Lake 2006; Wheatley and Gillings 2002).

GIS is often referred to as a single, powerful "tool" (Conolly and Lake 2006). This notion of geospatial technologies raises a debate over whether GIS is merely a tool, or a discipline in its own right (Conolly and Lake 2006). As Conolly and Lake explain, "this matters because if GIS is just a tool then its use may be construed as largely theoryneutral, but if it is a science then its use automatically brings with it a particular theoretical perspective" (2006: 3). I only briefly mention the theoretical implications for this study in the previous chapter, but in the following section I demonstrate that an application of GIS to this research is indeed theory-laden. This lends credence to the argument that GIS is a science in its own regard, and indeed emphasizes the interdisciplinary nature of GIS studies that involve archaeology and Earth sciences. However, this necessitates a strong understanding of the theoretical implications of identifying space as an important variable of study. Conolly and Lake point out that, "any kind of spatial analysis, whether formal or informal, is ultimately predicated on a concept of space" (2006: 3). For the purposes of this thesis, I will not go into detail on the long history of theoretical concepts of space. Rather, I will fast-forward to current applications 
of the relative concept of space, in which material objects are measured by their positional qualities (Conolly and Lake 2006). This spatial concept is central to archaeological studies of any scale. The archaeological interest in spatial relationships is well summarized by Wheatley and Gillings in the following:

Archaeologists have variously sought to explain spatial organization through factors such as adaptation to environmental conditions; territorial control...carefully structured and formalized intent...the result of a number of quasi-random post-depositional forces; the unplanned, accumulated and embedded product of everyday practice; pure chance; or some combination of all of the above.

Wheatley and Gillings, 2002:16

Since GIS is based on concepts of space, it also includes languages for referencing space and systems of organizing it (Conolly and Lake 2006). These specific technical terms, largely irrelevant to the focus of this study, will only be explained when used in the following chapters. However the systems of organizing space depends on topology and Euclidean geometry, which underlie even basic methods of measuring archaeological features, geological or geomorphological features, and units within the GIS applications (Conolly and Lake 2006; Hodder and Orton 1976). Topology is important in spatial analysis because it distinguishes objects differently by the manner in which they relate to other objects (Conolly and Lake 2006). The identification of discrete topological relationships is important to archaeological applications of GIS, specifically when studying stream drainages and other networks of features (Conolly and Lake 2006).

GIS in regard to archaeological settings, however, did not see any productive application until 1993, when Kvamme and van Leusen performed tests on environmental parameters and geomorphological properties (respectively) to study variance in site location (Conolly and Lake 2006). Since then, the theoretical implications of GIS studies 
have become increasingly sophisticated in archaeological research, and the technology of GIS as a tool has advanced rapidly (Conolly and Lake 2006; Howard 2007; Wheatley and Gillings 2002). Now GIS is fairly ubiquitous in the spatial analysis of archaeological data, even for uses as simple as creating graphics and maps (Wheatley and Gillings 2002).

This thesis draws heavily from two archaeological studies that explicitly use GIS to perform analyses on Paleolithic human-ecosystem interaction in Iberia (Burke et al. 2011; Garcia 2013). These researchers pursue similar questions about what site distribution may reflect regarding Middle and Upper Paleolithic responses to severe climate change.

\subsection{BACKGROUND AND APPLICATIONS OF LANDSCAPE APPROACHES IN ARCHAEOLOGY.}

High levels of environmental and cultural change have characterized several periods in human cultures. The adaptability of human culture is one of the trademark assets that have enabled the spread of the species across the planet, and the ever-increasing rise in social complexity. For all this perceived benefit, however, certain costs have been exacted upon the resources, prey, and environments that have seen human interaction. This section applies evidence supplied from archaeological and paleoenvironmental investigations within the analytical frameworks of resilience and Panarchy theories. Furthermore, a human behavioral ecology approach is applied to understand the decisionmaking processes employed by Paleolithic cultures in Central Portugal during a period of harsh environmental instability. The archaeological contexts of the discussions presented below are presented more fully in the following section of this chapter. 
Resilience theory and Panarchy are relatively young in terms of the lifetimes scientific schools of thought, but they offer great potential to archaeological and paleoenvironmental studies to gain a higher resolution understanding of past human behavior, human-ecosystem interactions, and the decision-making processes behind them. Panarchy and resilience theory offer explanatory systems for landscape-scale archaeology, and are concerned with the impacts of human predation, resource exploitation, and land-use strategies. The conceptual models within this theoretical perspective focus on how environmental pressures shape cultural and technological organization.

The challenge of understanding environmental change is complicated by difficulty in identifying appropriate spatial-temporal frames to study geological and paleoecological processes. As noted in previous and following sections, archaeologists studying Paleolithic cultural succession in Central Portugal struggle to identify fine-detail, smallscale changes due to the nature of climate and archaeological record. It is crucial to understand how so many diverse processes and factors interact and impact each other in dynamic Earth systems.

Information about environmental conditions during the Paleolithic is largely informed by proxy climate data. These sources of data are, by necessity, relatively stable collectors of millennial- and sub-millennial-scale fluctuations in temperature and compositional changes in the hydrosphere, cryosphere, biosphere, and lithosphere. The interconnectedness of Earth's climate systems makes proxy data an incredible asset to archaeological investigations of Paleolithic hunter-gatherer cultures, in which a great deal of cultural material evidence is invisible to archaeology. Ice cores, deep-sea sediment 
cores, and cave samples are used to reconstruct environmental conditions for Pleistocene Portugal.

North Atlantic Heinrich Event 2 (26.5-24.3 ka cal BP) is observable in diatom records from deep-sea cores taken off the Atlantic and Mediterranean coasts of Iberia (Cascalheira and Bicho 2013). These Heinrich events (HEs) impact sea-floor sediments through the formation of ice-rafted debris (IRD) layers in the ocean, which correspond to often-abrupt cooling phases (stadials) and are useful in reconstructing paleoclimate (Cascalheira and Bicho 2013). The implications of these climate data suggest that periods of drastic transitions to harsher, cold and arid conditions correlate with archaeological evidence for sudden, significant cultural shifts (Burke et al. 2011; Cascalheira and Bicho 2013; Haws and Bicho 2008).

The scope of observation for Paleolithic archaeology typically performs on a millennial scale due to the nature of stratigraphic and climate proxy data for the cultural period (Cascalheira and Bicho 2013). The models of Panarchy and resilience (Holling 2001) present a productive conceptual framework that offers explanations for the timing and behavioral dynamics of cultural phases in relation to environmental pressures (Cascalheira and Bicho 2013; Holling 2001; Holling and Gunderson 2002). A Repeated Replacement Model (RRM) is proposed as a productive explanatory model for the patchy, fragmented cultural record in Central Portugal, in which:

Climate-driven cultural change may have been accomplished completely by the total replacement of human populations (e.g. Neanderthals Modern Humans), or partially, by the reorganization of broken traditions under different social-cultural units.

Cascalheira and Bicho, 2013. Pp. 117 
The repeated replacement of human populations during the Pleistocene offers an explanation for difficulties in sequencing the succession of Paleolithic cultural phases. These researchers argue that, "the differentiation of Gravettian and Solutrean occupations, based on the technological characteristics of lithic industries, demonstrates the lack of any chronological overlap between the two cultural phases in Portugal" (Cascalheira and Bicho 2013). The RRM places geoarchaeological evidence for the region within the conceptual workings of Panarchy, and advances understanding of cultural succession during the Paleolithic (Cascalheira and Bicho 2013). These phases of cultural succession (further elaborated in the following section of this chapter) provide evidence for adaptive responses to harsh environmental changes.

Panarchy widely employs the Adaptive Cycle Model to explain techno-cultural changes related to human-environment interaction (Holling 2001; Holling and Gunderson 2002; Robbins 2004). Under this model, the dynamics of cultural and environmental change are described in four stages (figure 2.1). The Exploitation Phase ${ }^{\circledR}$ outlines general adaptive success, enabling rapid population growth and productive foraging and hunting efforts; the Conservation Phase (K) describes the techno-cultural diversification and intensification connected to diminishing return rates on resources and prey, and responses to environmental shifts (Cascalheira and Bicho 2013; Bicho and Haws 2008); the Release Phase $(\Omega)$, which describes cultural-environmental collapse; and the Reorganization Phase $(\alpha)$, in which a culture in crisis makes a sudden behavioral or organizational shift (Cascalheira and Bicho 2013; Holling 2001). 


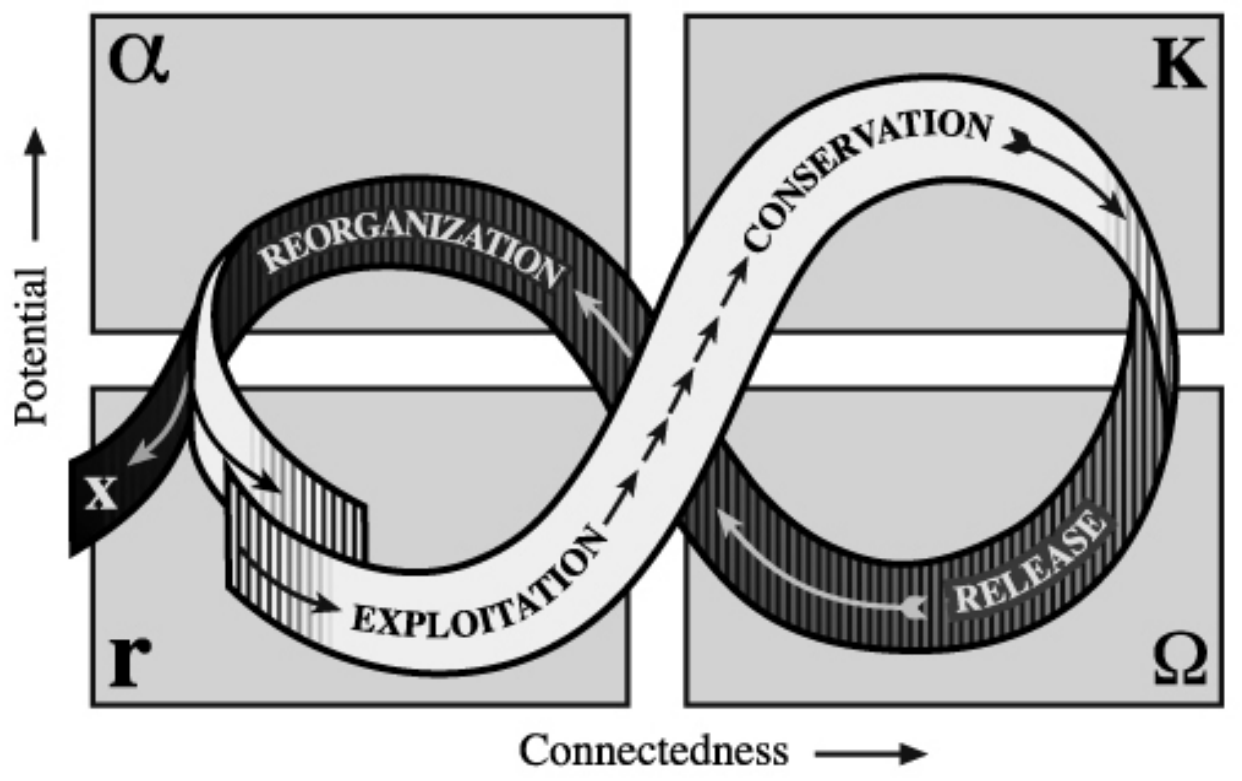

Figure 2.1 The Adaptive Cycle Model (Redman 1999).

This model is particularly useful for the complex adaptive conditions in Central Portugal during the Middle and Upper Paleolithic. Human groups of hunter-gatherers in the Middle Paleolithic might fall into the $r$ phase of the adaptive cycle, in which the exploitation of resource and prey patches relies on high returns in potential energy for adaptive fitness. The Panarchical processes and selective pressures described earlier drive $r$ strategists toward a $K$ phase, as subsistence strategies change and environmental pressures necessitate either a conservation or a reorganization, as observed in shifts toward diversification and intensification in lithic technologies (Redman 1999).

The end of the Middle Paleolithic, and transition to Upper Paleolithic displays a host of new techno-cultural complexes, as the Gravettian, Solutrean, and Magdalenian cultural phases are represented in the archaeological record in Central Portugal, and display behavioral and technological responses to rapid climate change at the LGM (Bicho and 
Haws 2008; Bicho et al. 2006; Cascalheira and Bicho 2013; Haws et al. 2010). These cultural phases, although archaeologically visible, appear to indicate decreased populations or even phases of abandonment in the Upper Paleolithic (Bicho and Haws 2008; Burke et al. 2011). The so-called "hiatus" during the Upper Paleolithic (Burke et al. 2011), however, presents some problems not only in determining archaeological succession, but also in defining complex human-environment interactions. As Cascalheira and Bicho explain, “[the] Release and Reorganization phases are, perhaps, the most significant for the RRM, as they represent the moment of crisis and subsequent restructuration of the socio-ecological systems" (2013: 117).

Several environmental triggers have been suggested for the onset of adaptive release and reorganization during the Middle-Upper Paleolithic transition, however HEs and associated Marine Isotope Stages (MIS) are closely linked in the chronological and environmental evidence of what little is understood of cultural succession for Portugal (Bicho and Haws 2008; Cascalheira and Bicho 2013). To avoid the conceptual trap of environmental determinism, and to clarify that these climate phenomena are not solely responsible, Cascalheira and Bicho add, "while HEs are, par excellence, the disturbance agents that trigger the actual change, patterns of reorganization tend to vary significantly, depending on a series of factors that include systems'...resilience" (2013: 117). The resilience of a system is broadly considered in the exploitative potential for human hunter-gatherers, and also for the ability of a habitat to recover from human impact to support sustained activity. Redman's concept of resilience (1999) would argue that, as the ecological impacts of human activity (hunting and gathering, in the case of Paleolithic Portugal) degrade the landscape in the human-ecosystem interaction, a crisis of 
realization must be approached as losses in productivity and diet breadth become observable. This process might be visible in the intensification of small mammal prey at inland caves during the Solutrean and subsequent shifts in lithic technology (Magdalenian), and addition of marine resources to diet breadth during the LGM (Bicho et al. 2006). However, a great deal of further archaeological investigation must be conducted to say this with any high degree of certainty. Nonetheless, shifts in huntergatherer subsistence throughout the Paleolithic remain central to recent and ongoing studies (see the following section of this chapter for a more thorough description of archaeological investigations and implications for this thesis).

The transfer of organizational schemes from the $K$ (conservation) phase to the $\Omega$ (release) phase may, in some instances, constitute a cultural collapse (Redman 1999). The $\alpha$ (reorganization) phase, however, represents a flip to a different state, as Robbins (2004) would describe it. In addition, panarchy accounts for nested scales of the adaptive cycle operating simultaneously, at different rates and scales, and with patchy distribution (Redman 1999). This pattern of distribution is suggested for Paleolithic occupation in Portugal in settings described as, "an arid landscape marked by isolated patchy floral and faunal habitats" (Cascalheira and Bicho 2013). The challenge, then, remains to define this process of degradation and recovery.

The concept of resilience in an ecosystem is a crucial component in explaining the environmental potential of an ecosystem, and also the limits of such potential. Four main assumptions underlie most discussions of ecosystems: (1) there is a punctuated equilibrium of episodic change through slow accumulation of "natural capital" with sudden release and reorganization; (2) patchiness of attributes and scale is stressed; (3) no 
single uniform equilibrium or control exists in an ecosystem; and (4) management strategies that rely upon fixed rules and assumptions for constant or ever-increasing yields are doomed to lose resilience (Holling and Gunderson 2002; Redman and Kinzig 2003). Another set of assumptions is based on the adaptive cycle model, which is generally ubiquitous among resilience theory research, including the assumption that change is inevitable and repeated, and that cycles appear across scales (Holling and Gunderson 2002; Redman and Kinzig 2003).

There are two main schools of thought about how resilience operates, and the methods and implications of research are dependent upon which approach a researcher takes. The first definition of ecological stability is termed engineering resilience, which "concentrates on stability near an equilibrium state, where resistance to disturbance and speed of return to equilibrium are used to measure the property" (Holling and Gunderson 2002: 27). This way of thinking about resilience assumes efficiency, control, constancy, and predictability, and lends itself well to rationalizing desires to develop and impact ecosystems. The other approach to studying ecological stability is termed ecosystem resilience, which "emphasizes conditions far from any equilibrium steady state, where instabilities can flip a system into another regime of behavior" (Holling and Gunderson 2002: 27). This framework measures the "magnitude of disturbance that can be absorbed before the system changes its structure by changing the variables and processes that control behavior" (Holling and Gunderson 2002: 28). Both approaches, however, stress a definition of resilience that relies upon variability in natural systems and interconnected, multi-tiered processes that impact each other from the top-down and bottom-up. 
Braudel established three basic scales of time, which have been instrumental to the development of resilience theory (Redman and Kinzig 2003). These timeframes consist of short-term processes that are typically catastrophic and relatively instantaneous, medium-span processes that are typically centennial in duration and capture social history, and the longue durée or long-term processes that encompass deep geologic time (Redman and Kinzig 2003; Robbins 2004).

The scale of observation is important in analyzing ecological resilience because the longue durée allows a higher resolution, more holistic understanding of spatial and temporal relationships in ecosystem change. There has been some criticism of the tendency in life, earth, and social sciences for paying "inadequate attention to the long time span and slow-moving processes that often underlie environmental crises" (van der Leeuw and Redman 2002: 597). However, the downside to meso- or macro-scale processes is reliance upon landscape- or regional-scale scopes of observation. As Cascalheira and Bicho warn, "the use of a wide geographical (Iberia) and cultural (traditional technocomplexes) scale does not always permit clear identification of the precise time and mode of population response to abrupt external changes" (2013: 118). This further complicates the ability to discern synchronicity of cultural-environmental change. As mentioned elsewhere in this thesis, broad levels of study are a necessity in Paleolithic archaeology, especially in Central Portugal. The geographic and environmental concordance throughout time at each occupation site lends a wide view that allows an observation of the continuum of the human-ecosystem interaction. Certainly at the range of several thousand years (as is often the case in the patchy chronologies available for Gravettian, Solutrean, or Magdelenian techno-complexes), 
landscape-level trends and other macroscale processes are revealed (Benedetti et al. 2009; Burke et al. 2011; Cascalheira and Bicho 2013; Fanning et al. 2009). This logic follows Robbins' (2004) model of irreversible levels of human impact as well, because observations in the archaeological and fossil record clearly indicate that anthropogenic pressure increases dramatically over time at almost all occupational sites throughout the Paleolithic. Furthermore, there is a robust debate among these disciplines over what exactly constitutes a 'crisis'. Differences in the scale of observation are illustrated in differing definitions of 'crises' between the more superficial role played by media, politics, and societal issues in comparison with the deeper time stressed by earth sciences (van der Leeuw in Fisher et al. 2011). Van der Leeuw (in Fisher et al. 2011) offers several concise examples and variations on the definition of a crisis, summing up that:

$[T]$ he problems seem to lie in the interaction between society and the environment. Most phenomena are not "simply" "events that occur in our environment." They are part of a co-evolution between people and their environment that links, in many insufficiently understood ways, social dynamics to the natural (i.e. "non-social") dynamics occurring in the environment.

van der Leeuw in Fisher et al., 2011. Pp. 43

A crisis can be observed when the human relationship to the environment ceases to be profitable or when the costs far outweigh the benefits, as in cases where there is land degradation, or a loss of natural productivity, loss of stability, or a loss of biodiversity (Robbins 2004; van der Leeuw in Fisher et al. 2011). This happens when changes in the natural or social environment occur that the human relationship can no longer sustain, or when the ability to process information becomes inadequate (van der Leeuw in Fisher et al. 2011). 
The hypothetico-deductive logic within panarchy research guides the application of generalized assumptions to inform hypotheses about specific interactions between humans and the ecosystem. The "nested hierarchies" of scale are used in panarchy to both reconstruct human impact in paleoenvironments, and to understand the current status the human-ecosystem relationship, as well as to predict its outcomes (Redman 1999; Redman and Kinzig 2003).

For the purposes of this thesis, I have deliberately used certain terms interchangeably, which would normally merit closer inspection and delineation. For example, in earlier discussions of panarchy and resilience, the concepts of scales and phases are often used interchangeably, with mention of mesoscale or second level Panarchical hierarchy. I feel the differences in terminology are negligible, and to labor over the details would detract from the goal of this paper to cover a lot of ground, synthesizing a large body of research and positions within ecological theory and apply it to specific research questions posed in archaeology and geology.

In conclusion, the point of scale is crucial in understanding human impact on the environment. In the case of Paleolithic hunter-gatherers in Portugal, lack of clear overlap in cultural successions may appear to be collapses, especially when strong environmental evidence suggests synchronicity between climate fluctuation and absent or diminished archaeological material (Benedetti et al. 2009; Bicho and Haws 2008; Burke et al. 2011; Cascalheira and Bicho 2013). Certainly, on the site level, small-scale periods of abandonment at some habitats could represent subsistence failure (Cascalheira and Bicho 2013). Expanding the view to the landscape level also fails to present an edifying picture of human activity in the trajectory through cultural transitions during the Upper 
Paleolithic. However the image of Upper Paleolithic adaptive strategies, on the macro scale, may be less dire. Proto-Solutrean (Cascalheira and Bicho 2013), Solutrean, and Magdalenian lithic technologies, along with an increased emphasis on marine resources in an expanded diet over time (Bicho and Haws 2008; Haws et al. 2010), allowed modern humans to reach levels of social complexity and species-level population numbers never before attained.

Landscape approaches that include Panarchy and resilience draw heavily from another theoretical perspective called Human Behavioral Ecology (HBE) (Winterhalder and Kennett 2006). While HBE sparks some contentious debate over its deficiencies in accounting for agency or its tendencies to gravitate toward deterministic arguments, the ecological models and concepts offer productive frameworks for explaining human behavior. As briefly discussed in the previous chapter, HBE is commonly employed as a conceptual framework to study diachronic human adaptations in the Paleolithic, but niche construction theory adds an emphasis on the changes brought about through human selection in ecosystems (Haws 2012). Ethnoarchaeological research from well documented hunter-gatherer societies are often applied as an archaeological analog to lesser-known prehistoric cultures (Bicho and Haws 2008; Kennett 2005; Winterhalder and Kennett 2006). This discussion of HBE is intended to add context to the previous section, which outlines a background of landscape approaches. Additionally, this section will set out some of the terms and assumptions that are referenced throughout the rest of this thesis.

HBE is well suited to the task of handling research questions dealing with human adaptation in relation to environmental contexts. It is designed to address behavioral 
variability and adaptive design over time, throughout fluctuating environmental and cultural pressures on human evolution. Some of the HBE models utilized in this thesis (where applicable) include diet-breadth, resource intensification, Central Place Foraging (CPF), and Ideal Free Distribution (alternately, the Ideal Despotic Distribution variant will be used when evidence of competition is observed). The ultimate goal in the application of these models to the Paleolithic in Central Portugal is to expand upon correlations between the material remains of human behavior and paleoenvironmental trends, as a function of adaptation - as has been observed and applied by several researchers (i.e. Bicho and Haws 2008; Burke et al. 2011; Cascalheira and Bicho 2013; Haws et al. 2010; Haws 2012).

Some of the conceptual models from HBE that have been applied to the Paleolithic in Central Portugal include: intensification, diversification, diet-breadth, rank (in regards to prey), cost, return rates, and site location (Bicho and Haws 2008; Cascalheira and Bicho 2013; Haws et al. 2010; Haws 2012; Shokler 2002). Models explaining foraging behavior that have been developed through archaeological research often use these terms to describe Paleolithic cultures, if only even indirectly through the use of certain data and citation of other researchers who openly describe HBE approaches (Burke et al. 2011; Garcia 2013). Researchers employing HBE models, even implicitly, borrow heavily from similar hypothetico-deductive conceptual frameworks and their interpretations citing clearly neo-Darwinian evolutionary theory - both of which feature commonly in established HBE research (Kennett 2005; Winterhalder and Kennett 2006). This is worth pointing out before later discussing the archaeological background of Paleolithic Portugal in the following section of this chapter. 
HBE outlines several key assumptions that rule the numerous models developed within this framework. Subsistence behavior is perhaps most important in describing HBE concepts. Optimal foraging theory (OFT) predicts that foragers will preferentially select food that represents some intersection of greatest potential energy return and least processing or transport cost; it also assumes that humans make rational decisions when foraging that tend to maximize options that give them the most amount of nutrient intake for the least amount of effort (Winterhalder and Kennett 2006). Diet-breadth models (a component of OFT) measure the distribution of resources and food across the landscape (Kennett 2005; Kennett and Winterhalder 2006). The location of resources and food sources in habitats are ranked by desirability and potential return on energy invested in procurement. Diet-breadth emphasizes efficiency in nutrient intake through optimization of ranked resources (Winterhalder and Kennett 2006). According to this model, a forager will collect lower ranked resources when higher ranked resources are unavailable, unproductive, or too costly to transport and process (Winterhalder and Kennett 2006).

This is particularly relevant in landscape applications of shifts between terrestrial and marine prey during the Upper Paleolithic in Portugal (Bicho and Haws 2008). Conditions observed in archaeological faunal remains suggest a shift during the Upper Paleolithic to broader diets, likely due to intensification of resources and technologies (Cascalheira and Bicho 2013; Bicho and Haws 2008; Burke et al. 2011; Haws et al. 2010; Shokler 2002; Thacker 1996). Climate and other environmental pressures certainly play a role in these factors, shaping potential losses in productivity among terrestrial game during the Middle Paleolithic (Benedetti et al. 2009; Bicho and Haws 2008; Haws et al. 2010), signaling a notable shift to emphasize greater presence of marine prey during cultural phases of the 
Upper Paleolithic (Bicho et al. 2006; Bicho and Haws 2008; Burke et al. 2011; Cascalheira and Bicho 2013).

Resource intensification occurs when a ranked resource is exploited with greater efficiency, enabling high short-term gains, however this comes at the expense of overall net returns as the resource patch fails to keep up with demand (Kennett 2005). Hockett and Haws define intensification to mean "an increase of labour input to extract higher yields from existing lands...either by increasing effort to extract more edible tissues from animal carcasses or by extracting additional animals or plants from a given unit of land" (2009: 2). As net returns decrease, optimization will signal a shift to lower-ranked resources to compensate for lowered nutrient-intake efficiency. This is where Central Place Foraging (CPF) models are applied, to measure optimization strategies in shifts to different ranked resource patches. Essentially, longer foraging trips require greater returns (Kennett 2005). CPF models also work to measure the optimization of habitat locations in response to prey and resource choices (Kennett 2005; Kennett and Winterhalder 2006). It is important to note that diet shifts do not necessarily represent an optimal subsistence strategy, but perhaps a last resort to maximize energy intake in an environment of diminished prey patches. Such is the paradox of 'successful' social organization: productive subsistence and habitat choice facilitate population expansion, which in turn requires more resources to support such growth, which in turn places a greater pressure on the ecosystem and further depresses prey value.

The diet choices and locations of habitats (or rather, archaeological localities, as we observe them now) is a very interesting subject for the Upper Paleolithic in Central Portugal, because there is some debate over the importance of marine resources and the 
chronology of their exploitation by hunter-gatherers (Burke et al. 2011). This remains to be tested for the region, and much like other research on Paleolithic subsistence, suffers from a lack of quality data.

The final HBE model I will discuss in this thesis regards the allocation of ranked resources throughout habitats. Questions about the implications for the patterning of sites are central to archaeological research on Paleolithic hunter-gatherers (Bicho et al. 2006; Bicho and Haws 2008; Burke et al. 2011; Garcia 2013). This spatial organization can be measured by HBE under two theoretical models - Ideal Free Distribution (IFD), and Ideal Despotic Distribution (IDD) (Kennett 2005; Kennett and Winterhalder 2006). IFD models emphasize patchiness in resource distribution and attempt to account for optimization in individual foraging behavior. IFD models follow the assumptions that individuals will behave rationally in making decisions about resource acquisition, and also that they are free to move to the next optimal habitat or resource patch when pressures indicate the need for a shift (Kennett 2005).

This may be observable in the patchiness of archaeological material cultural phases during the Paleolithic, yet there should be a predictable ubiquity of distributions according to the proximity of lithic resources and fresh water. However, HBE argues that when other individuals or groups are present, competition over resource patches and habitats limits optimal shifts. The despotic variant of these distribution models, IDD, measures competition and identifies buffer zones in the utilization of low-ranked resource patches and habitats (Kennett 2005). It may be possible that the inclusion of lesser quality resources such as quartz and quartzite in lithic assemblages in Portugal during the Upper Paleolithic (Burke et al. 2011; Shokler 2002; Thacker 1996) could represent a response to 
despotic pressure. These lithic materials are abundant and widespread throughout drainages and littoral zones due to their hard mineral composition (Burke et al. 2001; Shokler 2002; Thacker 1996), however their physical structure and cleaving properties do not lend themselves to tool manufacture as well as higher quality chert and jasper (Burke et al. 2011). A response to despotic pressure (i.e. competitive populations) is difficult to test for the Paleolithic, especially in Central Portugal where little archaeological evidence exists to support any figures for population sizes or densities. It would be expected that noticeable changes in habitat location would be observed throughout the succession of cultural phases during the Upper Paleolithic, if despotic pressure, loss of productivity, or the severe cold arid conditions of the LGM selected against settlement and subsistence behavior. However archaeological evidence appears to suggest a resilience that each successive cultural phase exploited through technological innovations and changes in diet. This is argued through models such as RRM (Cascalheira and Bicho 2013), BSR (Bicho and Haws 2008; Haws et al. 2010), and coastal ecosystem characteristics in which patchiness in the environment served as refugia for the late survivability of flora and fauna (Bicho and Haws 2008; Cascalheira and Bicho 2013).

\subsection{ARCHAEOLOGICAL CONTEXTS IN PORTUGAL: COASTAL AND INLAND SITES, AND PREVIOUS WORK RELATING TO THIS RESEARCH.}

This section presents a background of developments in the archaeology of the

Paleolithic in Portugal, and their contributions to this thesis research. These studies encompass long traditions of interdisciplinary research nested in broader archaeological contexts. As the following summary and discussion demonstrates, Paleolithic 
archaeology in Portugal is a microcosm of archaeological understanding, theory, and method throughout Iberia (Bicho 2009; Burke et al. 2011).

The archaeology of the Paleolithic in Portugal began in earnest in the late Nineteenth Century with the publication of several volumes on flint artifacts collected from Southern Portugal (Bicho 2009), and took on a more substantial role throughout the onset of the Salazar dictatorship of the early and middle Twentieth Century (Bicho 2009). Archaeological research on the Paleolithic continued in Portugal until "a hiatus of a few decades followed" (Bicho 2009), perhaps due to political and economic factors during an increasingly restrictive Salazar regime that finally came to a close with a military coup in the late 1970s and political stabilization shortly thereafter (Holton 2005). Archaeological investigations resumed in the 1980s with a renewed vigor in reconstructing prehistoric settlement in Portugal (Bicho 2009). However a lack of archaeological evidence for Paleolithic settlement and subsistence appears to have provided troubles since the inception of the subject of study. As Bicho notes of one of the notable early archaeological investigations, "Veiga states that he did not find any Paleolithic sites, but in his opinion it was likely that the Algarve was occupied by Paleolithic peoples since it is a landscape with many limestone caves of Jurassic origin" (2009: 185). This (implicit) acknowledgment of the importance of deep scales of time remains relatively constant throughout studies of the Paleolithic in Portugal. Proxy climate data, reliance upon geological studies of the area, and fairly low-resolution stratigraphic control in archaeological sites have all necessitated a broad scope of analysis for studying cultural succession and technological adaptations in the Paleolithic. Another description of early developments in understanding the Paleolithic comes can be found in notable works from 
almost 100 years ago that remain cited in somewhat recent research: "Beginning with the foremost piece by Breuil...still believed by many...the "Magdalenians" came across Europe, peopling the whole region in a short time span" (Bicho and Haws 2012). This notion of rapid colonization by Upper Paleolithic cultures remains fairly prominent in some research, however a greater emphasis on diachronic changes has shifted discussions of Magdalenian stone tool industries to highlight relative cultural succession in Portugal, rather than a single cultural group (Bicho and Haws 2012).

Archaeological investigations of the Paleolithic in Portugal have provided some rather fascinating and puzzling explanations for human activity in the face of rapidly changing contexts. Human population dynamics throughout the Paleolithic loosely reflect conditions observed elsewhere in Iberia, however the timing and exact nature of phases of biological and cultural succession present one of the biggest challenges in understanding the archaeology of Portugal; as Burke et al.. (2011: 26) note, "the archaeological record of Portugal is a microcosm of the Iberian record, with many of the same debates being played out, albeit on a smaller scale." While much of our knowledge of the Paleolithic is provided by relatively well understood, numerous, and high-profile sites in France and Spain, Portugal presents many outliers to patterns observed elsewhere (Burke et al.. 2011). For example, the existence of an early Aurignacian cultural component in Portugal is debatable, whereas its visibility is understood in Spain and France (Burke et al. 2011). Additionally, the unique localized environmental conditions of coastal Portugal may have provided refugia for the late survival of humans and other fauna (Bicho and Haws 2008; Burke et al.. 2011; Cascalheira and Bicho 2013). This 
bears implications for the appearance of Modern Human groups and techno-cultural successions into the Upper Paleolithic that are unique to Portugal.

Technological shifts at the end of the Middle Paleolithic, indicative of the transition from Neanderthal to Modern Human populations, are observed at several sites throughout Portugal (Burke et al.. 2011; Haws et al.. 2010). Some information for the Middle Paleolithic in Portugal is available from the site of Figuera Brava (Bicho and Haws 2008; Burke et al.. 2011), however much higher-resolution data has recently placed the cave site of Gruta da Oliveira in the forefront of understanding the Paleolithic in Central Portugal (Angelucci and Zilhão 2009; Trinkaus et al. .2007; Wilman et al.. 2012). Systematic surveys of the Tagus (Bicho 2009), Sado (Burke et al. 2011), and Alcoa River Basins (this volume) have also produced some Middle Paleolithic finds. However, as Burke et al. note, "the exact timing of the succession is difficult to establish" (2011:26). The issue of unclear patterns or rates of succession is not confined to the Middle Paleolithic. Burke et al.. (2011: 26) elaborate upon this for later cultural periods, in saying, "Early Upper Paleolithic (Aurignacian) industries are sparsely represented in Iberia and there is a noticeable delay in the timing of their appearance relative to Western Europe." This problem is repeatedly observed throughout several cultural phases in the archaeological record throughout Portugal, as some techno-complexes are more visible in some areas than others, and at varying times and intensities (Bicho and Haws 2008;

Burke et al.. 2011; Cascalheira and Bicho 2013). These factors observed in the Paleolithic archaeological record in Portugal highlight the importance of this region for archaeological research. The sequences of biological and cultural succession visible in 
the archaeological record reflect, to some varying extent, what is visible in the broader Paleolithic record for Western Europe (Burke et al.. 2011).

The Upper Paleolithic in the Estremadura is fairly well understood in comparison to other areas of Portugal (Angelucci and Zilhão 2009; Haws 2012; Trinkaus et al.. 2007; Wilman et al.. 2012). Indeed, by comparison, the uncertainty of the Upper Paleolithic seems a persistent and nagging element of research for other areas Portugal. While Bicho explains, "little is known about the final Upper Paleolithic from west of Gibraltar and south of the Tagus Valley...there is an important hiatus for the Tardiglacial phase of human occupation" (2009: 185). This assessment is repeated elsewhere in Portugal as well; "there is some evidence for a Lower Paleolithic presence but little or no evidence of an Upper Paleolithic occupation" (Burke et al.. 2011: 25). Burke et al.. (2011: 25) elaborate this in explaining, "the emerging pattern suggests either an occupational hiatus or a major shift in settlement pattern towards the end of the Middle Paleolithic." Gaps in the archaeological record (Cascalheira and Bicho 2013), diminished frequency of sites and lithic material (Bicho et al. 2006; Bicho and Haws 2008; Bicho 2009; Burke et al.. 2011; Haws et al.. 2010), and interpretations for the viability of habitats (Benedetti et al.. 2009; Burke et al.. 2011) form the evidence for the so-called hiatus during the Upper Paleolithic. Although Burke et al.. (2011) argue for regional abandonment of inland sites during the Upper Paleolithic in Southern Portugal, others suggest more balanced transitions for the Upper Paleolithic in Estremadura that include both marine and terrestrial resources (Bicho and Haws 2008; Cascalheira and Bicho 2013; Haws et al.. 2010). The relative abundance of information and numbers of archaeological locations in 
Estremadura once again emphasize the importance of this region for study in Paleolithic human adaptation.

The reasons for shifts in human technology and subsistence are largely attributed to climactic and ecological factors (Benedetti et al. 2009; Bicho et al. 2006; Bicho and Haws 2008; Burke et al. 2011; Cascalheira and Bicho 2013; Haws 2003; Haws et al. 2010). Burke et al. (2011) seem to question the certainty of cold, arid conditions featuring prominently as a catalyst for adaptive change in Portugal at the onset of the LGM, however subsequent work by Cascalheira and Bicho (2013) suggests that these environmental conditions are not in serious question. The synchronicity of HE2 with the beginning of the Solutrean (Cascalheira and Bicho 2013), as well as the concurrence of pollen sequences and deep-sea cores in Central Portugal (Bicho and Haws 2008), confirms the impacts of a harsh environment on Upper Paleolithic techno-culture (Benedetti et al. 2009; Bicho and Haws 2008; Cascalheira and Bicho 2013). Recent work by Benedetti et al. (2009) in paleoenvironmental reconstructions for Central Portugal shows consistent evidence of coastal and intertidal coniferous forests. Fluctuations between cold and arid stadials, and temperate interstadials, created widespread landscape instability (Benedetti et al. 2009). This is evident in the deposition and development of Early Holocene paleosols, overlying Late Pleistocene archaeological deposits (Benedetti et al. 2009). The sequence of semi-humid conditions preceding cold and arid periods, followed by loss of vegetation and erosion (Benedetti et al. 2009; Bicho and Haws 2008; Cascalheira and Bicho 2013) likely had incredible impacts on human populations, even on the millennial-scale oscillations projected by Bicho and Haws (2008). 
The ecological implications of drier, colder climate may have made available prey more vulnerable to human predation and population pressures, as the discussion of $\mathrm{HBE}$ in the previous section argues. Additionally, diversification of lithic technology and changes in prey choice during the Upper Paleolithic suggest adaptive shifts related to diet breadth (Cascalheira and Bicho 2013). Evidence for the broad-spectrum exploitation (Haws et al. 2010; Hockett and Haws 2002) of lower-ranked resources is evidence of population and resource intensification during the LGM. Upper Paleolithic sites in Iberia - and more specifically, Portuguese Estremadura - display marked increases in subsistence patterns emphasizing small mammal fauna (Haws et al. 2010; Hockett and Haws 2002), as well as shellfish (Burke et al. 2011; Cascalheira and Bicho 2013; Haws et al. 2010, Stiner 2003). This suggests a reliance on lower-ranked prey according to evolutionary ecological explanatory models, which results from competition, exploitation, and intensification. Additionally, signs of inland transport of coastal resources indicate population pressures consistent with HBE models suggesting intensification and competition (Bicho and Haws 2008). Bicho and Haws confirm diminishing return values in prey in explaining that, "marine animals, especially shellfish, came to be seen as marginal resources" (2008: 2167). Even though marine prey typically rank lowest in energy return schemes, depressed return values for terrestrial prey are assumed by increased prevalence of marine shell and fish bones in Upper Paleolithic archaeological contexts (Bicho and Haws 2008; Haws et al. 2010). Additional reasons for the exploitation of marine resources are offered, which include: low risk, high abundance, and low cost of collection (Bicho and Haws 2008; Winterhalder and Kennett 2006); habitat loss of inland locations (Bicho and Haws 2008; Burke et al. 2011); and 
alternatively, the ready availability of nutrients among marine prey (i.e. omega fatty acids) that are not present in terrestrial resources (Haws et al. 2010). These broad behavioral patterns have been interpreted from archaeological and environmental evidence, and provide robust explanatory frameworks for paleoecological reconstruction, yet the great challenge of prehistoric archaeology remains to understand cultural forces at work.

Although it is some evidence suggests that Upper Paleolithic settlement and subsistence shifted from terrestrial resources to an emphasis on marine prey during the LGM (Bicho and Haws 2008; Benedetti et al. 2009; Cascalheira and Bicho 2013; Haws et al. 2010), some debate exists over the finer-grained details of this ecologicalbehavioral change (Burke et al. 2011). This has much to do with the method of detection and sampling strategies employed during archaeological investigation. The issue of sampling and research design is a point to which I return after a brief discussion below of good examples of instances where researchers labor the details of their methodology (Barton et al. 2002; Burke et al. 2011).

Burke et al. (2011) propose a taxonomic organization for archaeological materials recovered during survey and surface collection. These categories are based primarily on the density and stratigraphic potential of surface scatters of lithic material, and are determined by applying kernel density measurements to point data attributes in a GIS (Burke et al. 2011). The values established in that study include: single finds; diffuse scatters; spatially discrete scatters; discrete dense scatters; sites; and localities (Burke et al. 2011: 30). The survey employed by Burke et al. (2011) preferentially sampled the Sado River Basin, which yielded somewhat unsurprising results. The study identified a 
majority of sites situated on landforms with low slope angle, located in the mid-basin area (Burke et al. 2011). Similar results are observed in analogous Late Pleistocene settings in arid Australia (Fanning et al. 2009; Holdaway and Fanning 2008). Geomorphological studies of Late Pleistocene archaeological contexts in arid environments argue that the results of this type of survey design are impacted by erosion and loss of sites at higher elevations, and consequent burial of low elevation sites by heavy sediment loads (Fanning et al. 2009; Holdaway and Fanning 2008). The geomorphological impacts to surface archaeological deposits in Estremadura differ, however, from contexts dominated by fluvial activity. Conditions in documented in ASEM studies emphasize soil deflation as the dominant site formation factor (Benedetti et al. 2009; Haws et al. 2010b). While the site categories set forth by Burke et al. (2011) are useful in the particular settings of ephemeral lithic scatters on fluvial terraces containing mixed Middle and Upper Paleolithic components, this taxonomic scheme may not be as effective in Estremadura, where Paleolithic localities are predominately located in upland landforms and dissected ridgelines between deeply incised drainages..

Barton et al. (2002) establish a taxonomic order to represent Paleolithic material scatters (albeit elsewhere in Iberia, in Palop Alto, Spain) that focuses more on intra-site patterning than the kernel density method used by Burke et al. (2011). This method, called the Settlement Intensity Index (SII), adds an ordinal derivative to simple artifact density values by the injection of time (Barton et al. 2002). The assignment of age values to artifact distributions offers the potential to understand a palimpsest of deposition in mixed-component surface sites (Barton et al. 2002). This extremely valuable contribution to Paleolithic archaeology, however, is rather difficult to accomplish in the narrow scopes 
of work offered by most field investigations. Such an undertaking not only requires mapquality plotting of surface artifacts (which can be expensive, difficult to operate the technology, and time-consuming), but also requires detailed field documentation and full lithic analysis (once again, very time and labor intensive). It is no wonder then that studies like the one performed by Barton et al. (2002), although important, are not done more often.

Another important study on the Paleolithic in Iberia that has significantly shaped this research is that of Garcia (2013) in the Cantabria region of Northern Iberia. This work establishes several productive analytical research designs in the application of GIS to Paleolithic localities in a region somewhat analogous to Portuguese Estremadura. conducted by Garcia (2012) attempts to bridge an objective comparison between the distribution of archaeological sites, and the settlement patterns of Paleolithic societies in Cantabria (Northern Iberian Peninsula). This method of spatial analysis is an important contribution to the study of prehistoric sites because, "it allows providing an approach to the settlement dynamics and mobility strategies of foraging societies" (Garcia 2012: 217). Garcia describes the Western Cantabrian region as, "a narrow, west-east oriented strip enclosed by the Cantabrian Sea to the north and the Cantabrian mountain chain to the south" (2013: 217). This area, characterized by short and wide rivers and steep, mountainous relief, is important for this kind of study because it has long been a classical region for archaeological research on the Paleolithic. The depth of knowledge about human (especially Magdalenian period) lifeways offers more robust data for GIS analysis.

The methods employed by Garcia (2013) are informed by two different kinds of factors used in the spatial analysis of archaeological sites. The first set of factors 
comprises site characteristics derived from direct observation. These include classification, altitude (both relative and absolute), topography, landscape, and aspect (Garcia 2013). These types of data are valuable to this sort of research design because identifying the key characteristics of data sets makes them more robust against smallscale fluctuations or outlying variables. The second set of factors defined as calculable variables, which includes insolation, viewshed, terrain, accessibility, distance to coast, or distance to water (Garcia 2013). GIS calculations of these types require a Digital Elevation Model (DEM) in order to effectively process data against complex variables. Garcia (2013) applies DEM files for landscape topography and elevation, as well as bathymetric data to his GIS analysis. The reason for including bathymetry in this study is such:

[t]he combination of topographical and bathymetrical cartography enabled the reconstruction of both mainland and submerged surface, thereby making it possible to approximate the Pleistocene coastal plain topography, by placing shoreline at _ 70 mbelow actual sea level (as an estimated sea level for the Late Glacial), and considering the surface between modern shoreline and the _70 $\mathrm{m}$ surface as land emerged during the Pleistocene.

Garcia, 2013. Pp. 219

Designing the GIS analysis to reference the Pleistocene landscape, rather than the current landscape, is an important step in using this type of study to provide explanations for past human site preferences. However, Garcia also designed the GIS to reference modern topography in order to form a "more solid basis for interpretations" by understanding the differences between both past and modern landscapes (2013:219). Upon establishing the DEM for the territory in question, insolation, or the seasonal and annual mean for sunlight throughout the day, was calculated to determine favorable areas that would have received adequate sunlight. Viewshed was also calculated, which Garcia 
describes, "is a classic issue in archaeological site location analyses, and has been regularly proposed as the main influencing factor for the understanding of sites and/or specific features distribution, such as megaliths" (2013: 219). For this study, visibility analysis focuses on the concept of site viewshed, or the visible landscape from a given site. A $10 \mathrm{~km}$ radius from each site was calculated to simulate human visible range, and the visual fan for each site was divided into eight sectors corresponding to a $45^{\circ}$-azimuth arc (Garcia 2013). Terrain was also categorized on a broad, four-tiered hierarchy, to designate sites located on different landscapes where differential hunting or other behavioral factors are considered to impact site location. These four categories are comprised of: level terrain, hilly terrain, abrupt terrain, and steep terrain (Garcia 2013). These are easily calculated based on topographic DEM files. Site accessibility was also calculated, which Garcia (2013) adapts from site catchment and weighted task surface analyses. The method employed in this study, Cost of Weighted Movement Index (CWMI), attempts to address the cost-benefit decision-making of mobile hunter-gatherers during the Paleolithic. Finally, distance to water and distance to coast were calculated to determine settlement location choices. Distance to water and coast is of immense importance in prehistoric hunter-gatherer societies due to the impacts that resource intensification has on the exploitation of marine prey. For this reason access to the coast would have likely been a deciding factor for Paleolithic settlement. In order to calculate accessibility to the coast, Garcia (2013) considered a least accumulated cost path from each site to the nearest shoreline. Least accumulated cost paths are determined by first generating a friction surface similar to the CWMI, that accounts for the energy required to move across terrain toward the coast. In this study, river crossings were not taken into 
factor because the assumption was made that rivers would be followed to the coast, rather than crossed (and adding further risk and cost to movement). The productive methods of connecting landscape-scale spatial trends to indicators of human behavior applied in Garcia's study (2013) provide an approximate template from which this research was adapted to fit the data sample for Paleolithic localities in Estremadura.

Another challenge facing Paleolithic archaeology in Portugal is that of understanding lithic assemblages (Shokler 2002). Shokler (2002) argues that researchers encounter myriad problems in identifying and sourcing flint in archaeological contexts. The high degree of variability in appearance and physical properties of this material adds additional strain for researchers attempting to study its temporal-spatial distribution in Paleolithic archaeological contexts (Shokler 2002). Detailed intra-nodular analyses of flint outcrops, Shokler argues, "provide a strong means of controlling observed intraformation and intranodular variability as well as a means by which secondary geologic sources can be used in lithic sourcing studies" (2002: 176). Much like the issues plaguing detailed site patterning, such an intensive study of lithic sources is very important in adding contexts to archaeological cultures, but often not within the feasibility of field projects.

Returning to the problem of an Upper Paleolithic "hiatus" in Portugal (Bicho 2009; Bicho and Haws 2008; Burke et al. 2011; Cascalheira and Bicho 2013), it seems such a question is not answerable with the current information available. Evidence to support a sudden decrease in population might imply a localized die-off of human groups (such as the RRM proposed by Cascalheira and Bicho 2013), which would require skeletal data to confirm a population bottleneck, and a paltry low number of skeletal specimens are 
available for the Paleolithic. Such a low number of archaeological locations exist with lithic material suggesting Upper Paleolithic occupation, yet at the same time such a limited amount of potential locations exist due to erosion, land-use, and other postdepositional forces (Benedetti et al. 2009). As I have attempted to explain in this section, it is possible that work-arounds for more productive sampling and data recovery exist; however, these methods will entail more labor, technology, and time than typically feasible in a project's scope of work. Additionally, more advanced field methods require thorough theoretical guidance in order to achieve higher levels of effectiveness.

So, here we come to understand that project design shapes sampling strategies, and subsequently the kind of data gathered and the kind of interpretations that can be supported. The research presented above on spatial-temporal analysis (Barton et al. 2002; Burke et al. 2011), and lithic analysis (Shokler 2002) each make valuable contributions aside from the data interpretations - they all describe, in detail, the sampling strategies, methods, and relevant theoretical backgrounds employed in the study. This is particularly valuable for newcomers to this particular focus of study in providing a template from which to repeat tests and swap out other variables. The following chapter explains the methods for this study, and draws heavily from the archaeological, theoretical, and geospatial backgrounds provided above. 


\section{CHAPTER 3: METHODS}

\subsection{ARCHAEOLOGICAL SURVEY METHODS}

Although extensive excavation projects and subsurface testing have significantly contributed to the ongoing research in Portuguese Estremadura, it is the results of archaeological survey that inform this research the most. Geological survey has also been a component of fieldwork in this area, and the surface geomorphology certainly guides archaeological knowledge, however it may be useful in to treat these investigations as handmaiden to archaeological survey in the context of this research. This treatment is useful, especially on a larger scale, since both components of fieldwork inform the GIS data used here. For this reason, more attention is given in this section to the methods of survey and reconnaissance than to archaeological or geological excavation techniques. This section also presents the rationale and value of including a robust field survey component in archaeological research.

The methods for this pedestrian survey largely entail reconnaissance and opportunistic surface collection. Areas of potential for Paleolithic cultural material were identified in two basic ways. First, a geologic map of the research area was consulted to identify sediments of Pleistocene age, as well as to locate areas of high potential for 
exposed sediments (and therefore potential for Paleolithic cultural deposits). These landforms typically consist of headlands and coastal bluffs in the Holocene dune fields, where erosion and land use result in exposed sediments of Pleistocene age or older. Other areas of high potential for Paleolithic localities tend to include agricultural fields, as deep plowing and erosion have exposed Late Pleistocene-Early Holocene cultural material (Benedetti et al. 2009; Bicho and Haws 2008; Haws et al. 2010). Second, the ASEM project made attempts to identify high-potential areas through inspecting aerial and satellite imagery for surface visibility (i.e. plowed fields, eucalyptus stands, orchards, etc.). This method, however proved unproductive since aerial photos were too old and the satellite data too coarse-grained to be ground-truthed in determining feasibility of surface inspection. "Ground-truthing" is a term popularly applied to field methods that confirm or reject conditions observed through remote sensing techniques (Wheatley and Gillings 2002). In this case, areas suspected to exhibit high surface visibility are first identified through specialized mapping or aerial reconnaissance, and then are confirmed by visual inspection. Ground-truthing is extremely valuable in evaluating the efficacy of remote sensing methods, and in turn guides the expected outcomes of research questions when realistic goals are understood in the field. The research later presented in this thesis aims to test several variables in the spatial organization of sites, as well as any patterning relationships that may exist.

The ASEM project (Haws et al. 2010) used the methods described above to guide field investigations. Once areas of high probability for Paleolithic sites were identified, field teams consisting of graduate and undergraduate students spread out to systematically cover the survey area with visual inspection. In areas of high surface 
visibility (i.e. plowed fields and eucalyptus groves), surveyors walked transects 3-5

meters apart until the area was covered. In areas where terrain and vegetation reduced surface visibility, opportunistic visual inspection was conducted whenever conditions permitted surface visibility. Surface collection was conducted upon the identification of lithic cultural material, typically consisting of the likely Paleolithic chert flakes and flake tools. However, lithic material from more recent cultural periods were also identified and collected. Shovel test excavations were not conducted,because of permit protocols. Systematic shovel test survey does not exist in Portugal because it is not recognized as a component of archaeological survey methods.

The inclusion of archaeological survey is especially crucial to forming an understanding of regional-scale site relationships (David and Thomas 2008; Hodder and Orton 1975; Howard 2007). During archaeological survey, the size and scale of sites are often described solely in terms of horizontal surface area. Without excavation, or shovel test probes, it is difficult to assess the depth of a site, what Hodder and Orton describe, "hierarchical organization" (1975: 55). However, it is possible to gain a sense of this when the surface scatter is "a palimpsest of distributions of different dates" (Hodder and Orton 1975: 54). This is certainly the case in several archaeological surface scatters in which the original soil matrix has eroded since deposition, and deposited lithics from multiple cultural periods in a locality. As previously discussed in earlier sections of this research, site survivability depends on the cultural material and upon depositional and taphonomic processes (Fanning et al. 2009; Hodder and Orton 1975). In the case of the Paleolithic sites identified in Portuguese Estremadura, lithic artifacts are often the only 
indicator for the presence of a surface site due to the age of deposition, the acidic soils, and the high degree of weathering and erosion in the area.

Hodder and Orton have argued that, "although the factors influencing the recovery of archaeological material in one area may change through time, the overall pattern of finds may in certain cases not vary significantly" (1975: 54). Others working in Iberia have also noted that seemingly drastic changes in the landscape since the Paleolithic may have little effect on the distribution of cultural material (Barton et al. 2002; Garcia 2013). These mixed-component surface scatters are the most common form of archaeological deposits in Portuguese Estremadura and, despite a lack of stratified subsurface potential, these deflated "archaeological surfaces" (Fanning et al. 2009; Holdaway and Fanning 2008) offer visible palimpsests of material culture throughout the Paleolithic.

These concepts inform the use of 'locality' to refer to locations where Paleolithic material was recovered. This follows in the methods of Barton et al. $(2002 ; 2013)$ working in similar contexts, as well as employs theoretical frameworks that account for human agency in the behaviors that lead to the deposition of material culture (Hodder and Orton 1976; Schiffer et al. 1978; Schiffer and Skibo 2008). The term, locality, is preferred for a deposit of archaeological material that is difficult to define in areal extent and stratigraphic depth, because this classification is not laden with assumptions of form and function (Schiffer et al. 1978; Shiffer and Skibo 2008). 'Locality' also represents the use of behavioral ecological frameworks by implying an understanding for "the cultural and noncultural processes that create the archaeological record" (Shiffer and Skibo 2008: 6). To elaborate upon this, HBE, "is based upon the simple premise that behavior...proximately forms the archaeological record through making, using, and 
disposing of material items" (Schiffer and Skibo 2008: 6-7). However, traditional

definitions and terminology referring to archaeological deposits fail to account for agency and variability in the formation processes that are at the heart of contemporary archaeology (Schiffer and Skibo 2008). The acknowledgement of behavioral chains in the deposition of cultural material also marks a departure from more utilitarian conceptions of the manufacturing process, or chaine opératoire, in which the post-manufacture processes of material use and discard are considered (Schiffer and Skibo 2008).

Some sites in Estremadura, however, do occur in stratified contexts, like Praia Rei Cortiço, associated with peat deposits that preserve macro- and microbotanical remains and provide valuable information about the environment during the Paleolithic (Haws et al. 2010a, 2010b). These sites are unfortunately a rare exception, though they do offer high-resolution data that adds precision to observable trends at other sites in the region. Cave sites offer more control with far better preservation that includes faunal remains as well as other macro-artifacts, and have added a great deal of understanding of Paleolithic behavior to the archaeological record (Angelucci and Zilhão 2009; Garcia 2013; Haws et al. 2010b; Trinkaus et al. 2007; Wilman et al. 2012).

\subsection{GIS METHODS}

GIS point data in this study is collected from archaeological survey and reconnaissance in the field, which include Paleolithic sites and localities. Wheatley and Gillings define "points" as broadly consisting of "many occasions when archaeologists have spatial observations that are not measured on a numerical scale at all...instead, we may have points that represent observations that something is merely present at a 
particular location" (2002:185). This is certainly the case for this regional study of Portuguese Estremadura, which looks at various archaeological entities that may be considered sites, lithic scatters, isolated finds, etc. yet they are all represented with point data. The value of this source of information lies in the ability to attach additional attributes such as size, period, object classifications, and other artifact descriptors to a spatial reference (Wheatley and Gillings 2002). This contribution to ASEM and to this own research includes the addition of attribute fields to point data, which builds upon data from past archaeological surveys with ASEM and other projects. It is necessary to connect this mention of points to the actual function it serves in archaeological GIS analysis, so the following section describes the methods and purpose of GIS analysis in this study.

Localities of Paleolithic archaeological deposits have been documented through the use of hand-held GPS units for several years with field projects underway in Portugal (see Bicho 1994, 2009; Haws 2004, 2006; Haws et al. 2010). A discussion of the terminology regarding archaeological "localities" rather than "sites" is offered in the theoretical background, but here I use locality to accommodate the wide range of areas of interest to archaeological study. Additionally, a discussion of the theoretical implications of the treatment of 'concepts of space' in GIS (Connolly and Lake 2006) is also presented in the theoretical background section. In 2013, I used a Garmin GPS 60 hand-held GPS unit that consistently recorded site locations within two to three meters of accuracy. All point data was recorded in UTM WGS 84 format, chosen because a great deal of the GIS data available for this project is also referenced on the WGS 84 datum. I created an attribute table for archaeological sites derived from previous fieldwork (Haws et al. 
2010a, 2010b; Haws 2012) as well as the author's participation on archaeological survey and reconnaissance in 2012 and 2013. The information for these sites has been restricted to localities that include Paleolithic cultural material, presented in the following chapter. The fields recorded in the attribute table include UTM coordinates, site name or field designation, cultural period, general time period, elevation (recorded by the handheld GPS unit), and general site notes.

The GIS program used in this study is ArcGIS version 10. This GIS program has been almost universally applied throughout archaeological investigations, as well as in many other fields requiring spatial analysis or representation. Point data was logged during archaeological survey and reconnaissance, and entered into a table to be imported into a GIS. In addition to the point data collected from archaeological localities, the ASEM project purchased raster, vector, line, and shape data encompassing the geographic and physical domains within our project area. A low-resolution Digital Elevation Model (DEM) encompassing the study area will be used to perform several elevation-based calculations. This DEM is sourced from data collected by the Advanced Spaceborne Thermal Emission and Reflection Radiometer (ASTER), and features a 30-meter resolution. This DEM and hydrology shapefiles were downloaded from the United States Geological Survey (USGS) Earth Explorer tool (http://earthexplorer.usgs.gov).. Additional shapefiles were provided by Agência Portuguesa do Ambiente (APA), a service of the Portuguese ministry of agriculture and environment. The APA files include vector data for insolation, geology, lithology, elevation, bathymetry, and hypsometry. These files are used to augment the low-resolution DEM and to produce preliminary models for more robust GIS analyses. 
The data in this study is used to demonstrate a number of relationships between Paleolithic settlement and the environment, as well as highlighting some of the problems inherent to paleoenvironmental reconstructions. As discussed more thoroughly in other sections of this study, problems arise in the inference of Paleolithic settlement when models are derived from presently observed environmental features. The assumptions underlying this method of producing paleoenvironmental models often fail to account for potentially drastic changes to the landscape, hydrology, and ecology that have occurred since the Last Glacial Maximum. In short, the modern environment may serve as a weak or invalid analog for the Pleistocene environment. Nonetheless, the ability of GIS analysis to produce models for prehistoric behavior is limited by a lack of data. The use of modern environmental and terrain data, then, is performed out of necessity for lack of viable alternatives. However, arguments on Paleolithic features derived from modern data still benefit from information from archaeological investigations and environmental proxy data.

Despite inherent limitations in studying a reconstructed landscape, there are certain benefits to a research design that uses modern data to model Paleolithic settlement. Garcia (2013) employs this research approach to demonstrate further evidence supporting coastal-inland movement patterns during the Upper Paleolithic. Modern landscapes are applicable in the study of Paleolithic settlement and subsistence on a general level, but caution should always be used when making more detailed inferences. Landscape-scale approaches are useful units of observation for general patterns, especially given the small sample size of Paleolithic sites available for study. Unfortunately, fine-grained data on the Paleolithic environment is not yet available for smaller scale, site-level analysis. This 
method of spatial analysis, referencing modern environments, is an important contribution to the study of prehistoric sites because, "it allows providing an approach to the settlement dynamics and mobility strategies of foraging societies" (Garcia 2013: 217). The depth of knowledge about human (especially Upper Paleolithic) lifeways offers more robust data for GIS analysis.

The methods employed by Garcia (2013) are informed by two different kinds of factors used in the spatial analysis of archaeological sites. The first set of factors comprises site characteristics derived from direct observation. These include classification, altitude (both relative and absolute), topography, landscape, and aspect (Garcia 2013). These types of data are valuable to this sort of research design because identifying the key characteristics of data sets makes them more robust against smallscale fluctuations or outlying variables. The second set of factors defined as calculable variables, which includes insolation, viewshed, terrain, accessibility, distance to coast, or distance to water (Garcia 2013). GIS calculations of these types are possible despite limitations with DEM resolution, because spatially referenced vector or raster data can be used for distance measurements,

Similarly to Garcia (2013), this study utilizes a DEM in order to perform GIS calculations of these types, and to process data against complex variables. Following the conclusions derived from Garcia's research on Paleolithic Cantabria (2013), I argue that elevation is an unlikely variable in site location. Likewise, terrain factors are unlikely correlates in influencing site distribution. However, as Garcia (2013) demonstrates, variables such as insolation, and distance to water or coastline are likely to play significant roles in determining site location. The approach used in this study to apply 
GIS to the archaeology of Paleolithic Portugal differs from works like Garcia (2013) and Burke et al. (2011) in this study's use of specific geologic contexts for control over site patterning. Here, I determine distribution patterns by a regression analysis of Paleolithic sites in association with Late Pleistocene-Early Holocene sediment exposures. Additionally, I place the locations of these sediment exposures within broad categories of terrain characteristics. The broad, four-tiered hierarchy established by Garcia (2013) to designate sites includes: level terrain, hilly terrain, abrupt terrain, and steep terrain. However, the environment in Portuguese Estremadura differs notably from Cantabria. The ultimate goal of this GIS analysis of Paleolithic sites is to create a starting point for future GIS studies and developments in landscape-scale approaches to understanding site distribution and human-ecosystem interaction during the Paleolithic. The development of this research is intended to aid future archaeological field investigations in considering broader implications of scales of Panarchy, human behavioral models, and spatial organization when identifying and excavating Paleolithic sites. 


\section{CHAPTER 4: RESULTS}

\subsection{ARCHAEOLOGICAL SURVEY RESULTS}

This research uses point data collected during archaeological surveys with the ASEM project that have been stored in a database. This database includes points for archaeological sites, geomorphological sample sites, landscape features, chert sources, survey areas, and spatial bracketing points. A query for archaeological locations produced 315 separate entries comprised of isolates, open-air sites, and caves and rockshelters where archaeological material has been recovered in Estremadura. Further selection among these points yielded 76 locations containing material dated to the Paleolithic (17 Middle Paleolithic, 59 Upper Paleolithic), shown below (Figure 4.1). Some of these Paleolithic locations have been identified with more specific cultural affiliations (i.e. Mousterian, Gravettian, Solutrean, Magdalenian) when diagnostic material is present. These sites are presented in table 4.1 below. An additional 198 archaeological locations are identified as indeterminate lithic scatters, and many of these are suspected to contain Paleolithic material. A bulk of the lithic material collected from surface scatters during archaeological surveys has not yet been analyzed, so these indeterminate localities are not presented in this research. More complete lithic analyses 
of the Paleolithic assemblage for Portuguese Estremadura will undoubtedly expand this sample size and add further details on cultural phases present.

The condition of many of these Paleolithic locations represents a palimpsest of accumulative deposits that have subsequently been impacted by post-depositional forces, resulting in the mixed-component surface sites that characterize the archaeological record for the Estremadura (Benedetti et al. 2009; Shokler 2002; Thacker 1996). Although some may argue that the condition of these surface deposits indicates a loss of data and exhibits low potential to gain further knowledge of Paleolithic settlement and subsistence, the concept of "archaeological surfaces" (Fanning et al. 2009; Holdaway and Fanning 2008) presents some possibilities for interpretation. Many of the Paleolithic locations in Portuguese Estremadura consist of open-air lithic material scatters that exhibit poor site integrity in the form of extensive disturbance, deflation of soils, and poor stratigraphic control through mixing of deposits (Barton et al. 2002; Bicho and Haws 2008; Burke et al. 2011; Cascalheira and Bicho 2013). Despite these site conditions, there is still a great deal of information about Paleolithic settlement and subsistence behavior that is quite visible at larger spatial scales of observation. It is this increased scale of focus that emphasizes the strengths of GIS as an analytical method for understanding landscapescale patterns in spatial organization. The GIS analyses of features that indicate human decision-making strategies and settlement and subsistence behavior are presented in the following results. 


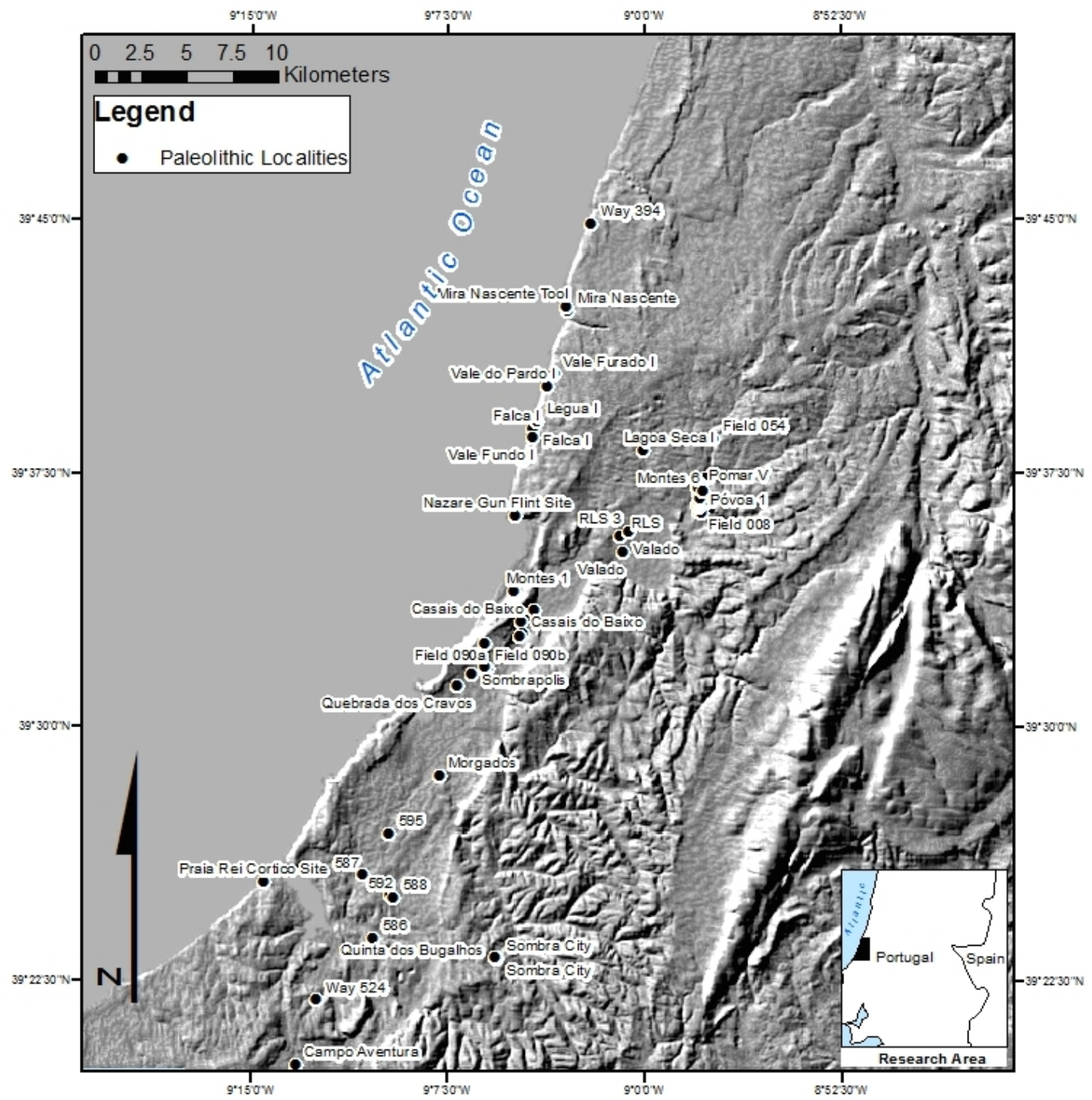

Figure 4.1 Paleolithic Sites in Portuguese Estremadura 


\begin{tabular}{|c|c|c|c|c|}
\hline Locale Name & Locale Code & Locale Type & Time Period & General Time \\
\hline Badger Cave Road & site & open air & Upper Paleolithic & \begin{tabular}{|l|} 
Upper Paleolithic \\
\end{tabular} \\
\hline Casais do Baixo & site & open air & Paleolithic & Upper Paleolithic \\
\hline Cova das Lapas & site & cave & \begin{tabular}{|l} 
Middle Paleolithic \\
\end{tabular} & Middle Paleolithic \\
\hline \begin{tabular}{|l|} 
Valado \\
\end{tabular} & site & open air & \begin{tabular}{|l} 
Magdalenian \\
\end{tabular} & \begin{tabular}{|l} 
Upper Paleolithic \\
\end{tabular} \\
\hline \begin{tabular}{|l|} 
Valado \\
\end{tabular} & site & open air & Late Upper Paleolithic & \begin{tabular}{|l|} 
Upper Paleolithic \\
\end{tabular} \\
\hline Falca I & site & open air & Upper Paleolithic & Upper Paleolithic \\
\hline Falca I & site & open air & Late Upper Paleolithic & Upper Paleolithic \\
\hline Field 001B & site & open air & Magdalenian & \begin{tabular}{|l|} 
Upper Paleolithic \\
\end{tabular} \\
\hline Field 001B & site & open air & Gravettian & Upper Paleolithic \\
\hline \begin{tabular}{|l|} 
Montes 5 \\
\end{tabular} & site & open air & Upper Paleolithic & \begin{tabular}{|l|} 
Upper Paleolithic \\
\end{tabular} \\
\hline Montes 3 & site & open air & Upper Paleolithic & Upper Paleolithic \\
\hline \begin{tabular}{|l|} 
Field 007 \\
\end{tabular} & site & open air & Upper Paleolithic & \begin{tabular}{|l|} 
Upper Paleolithic \\
\end{tabular} \\
\hline Montes 2 & site & open air & Middle Paleolithic & Middle Paleolithic \\
\hline Field 008 & site & open air & Magdalenian & Upper Paleolithic \\
\hline Field 008 & site & open air & Upper Paleolithic & Upper Paleolithic \\
\hline Field 008 & site & open air & Gravettian & Upper Paleolithic \\
\hline Montes 8 & site & open air & Upper Paleolithic & Upper Paleolithic \\
\hline \begin{tabular}{|l|} 
Montes 9 \\
\end{tabular} & site & open air & Magdalenian & Upper Paleolithic \\
\hline \begin{tabular}{|l|} 
Póvoa 1 \\
\end{tabular} & site & isolate & Magdalenian & Upper Paleolithic \\
\hline Field 054 & site & isolate & Upper Paleolithic & Upper Paleolithic \\
\hline \begin{tabular}{|l|} 
Morgados \\
\end{tabular} & site & open air & \begin{tabular}{|l} 
Middle Paleolithic \\
\end{tabular} & Middle Paleolithic \\
\hline Field 090a & site & open air & Magdalenian & Upper Paleolithic \\
\hline Field 090b & site & open air & Magdalenian & Upper Paleolithic \\
\hline Casais do Baixo & site & open air & Middle Paleolithic & Middle Paleolithic \\
\hline Sombra City & site & open air & Late Upper Paleolithic & Upper Paleolithic \\
\hline Sombra City & site & open air & Late Upper Paleolithic & \begin{tabular}{|l|} 
Upper Paleolithic \\
\end{tabular} \\
\hline \begin{tabular}{|l|} 
Montes 11 \\
\end{tabular} & site & open air & Upper Paleolithic & \begin{tabular}{|l|} 
Upper Paleolithic \\
\end{tabular} \\
\hline Field 106b & site & open air & Upper Paleolithic & Upper Paleolithic \\
\hline Montes 12 & site & open air & Upper Paleolithic & Upper Paleolithic \\
\hline Montes 12 & site & open air & Middle Paleolithic & Middle Paleolithic \\
\hline Montes 10 & site & open air & Solutrean & Upper Paleolithic \\
\hline Montes 10 & site & open air & Mousterian & Middle Paleolithic \\
\hline Montes 15 & site & open air & Paleolithic & Upper Paleolithic \\
\hline \begin{tabular}{|l|} 
Montes 14 \\
\end{tabular} & site & open air & Upper Paleolithic & \begin{tabular}{|l|} 
Upper Paleolithic \\
\end{tabular} \\
\hline \begin{tabular}{|l|} 
Montes 18 \\
\end{tabular} & site & open air & Upper Paleolithic & \begin{tabular}{|l|} 
Upper Paleolithic \\
\end{tabular} \\
\hline \begin{tabular}{|l|} 
Lagoa Seca I \\
\end{tabular} & site & open air & Magdalenian & \begin{tabular}{|l|} 
Upper Paleolithic \\
\end{tabular} \\
\hline Lagoa Seca I & site & open air & Gravettian & Upper Paleolithic \\
\hline Legua I & site & open air & Magdalenian & Upper Paleolithic \\
\hline Mira Nascente & site & open air & Middle Paleolithic & Middle Paleolithic \\
\hline Mira Nascente Tool & site & isolate & Middle Paleolithic & Middle Paleolithic \\
\hline Nazare Gun Flint Site & site & open air & Solutrean & \begin{tabular}{|l|} 
Upper Paleolithic \\
\end{tabular} \\
\hline Pomar dos Pessegos I & site & open air & Gravettian & \begin{tabular}{|l|} 
Upper Paleolithic \\
\end{tabular} \\
\hline \begin{tabular}{|l|} 
Pomar dos Pessegos I \\
\end{tabular} & site & open air & Magdalenian & Upper Paleolithic \\
\hline Pomar dos Pessegos I & site & open air & Upper Paleolithic & Upper Paleolithic \\
\hline Pomar dos Pessegos II/Pomar IV & site & open air & Upper Paleolithic & Upper Paleolithic \\
\hline Pomar dos Pessegos II/Pomar IV & site & open air & Gravettian & Upper Paleolithic \\
\hline Pomar dos Pessegos II/Pomar IV & site & open air & Solutrean & \begin{tabular}{|l|} 
Upper Paleolithic \\
\end{tabular} \\
\hline Pomar dos Pessegos II/Pomar IV & site & open air & Magdalenian & Upper Paleolithic \\
\hline Pomar dos Pessegos III & site & open air & Mousterian & Middle Paleolithic \\
\hline Pomar V & site & open air & Upper Paleolithic & Upper Paleolithic \\
\hline \begin{tabular}{|l|} 
Praia do Norte I \\
\end{tabular} & site & isolate & Upper Paleolithic & \begin{tabular}{|l|} 
Upper Paleolithic \\
\end{tabular} \\
\hline Praia do Norte II & site & open air & Upper Paleolithic & Upper Paleolithic \\
\hline Praia do Norte III & site & isolate & Upper Paleolithic & Upper Paleolithic \\
\hline Praia Rei Cortico Site & site & open air & Mousterian & Middle Paleolithic \\
\hline \begin{tabular}{|l|} 
Quinta do Pescaria \\
\end{tabular} & site & open air & Upper Paleolithic & Upper Paleolithic \\
\hline Vale do Pardo I & site & open air & Mousterian & Middle Paleolithic \\
\hline Vale Fundo I & site & open air & Upper Paleolithic & Upper Paleolithic \\
\hline \begin{tabular}{|l|} 
Vale Furado I \\
\end{tabular} & site & open air & Upper Paleolithic & \begin{tabular}{|l} 
Upper Paleolithic \\
\end{tabular} \\
\hline \begin{tabular}{|l|} 
Casais do Baixo 2 \\
\end{tabular} & site & open air & Upper Paleolithic & \begin{tabular}{|l|} 
Upper Paleolithic \\
\end{tabular} \\
\hline Way 394 & site & isolate & Paleolithic & Upper Paleolithic \\
\hline 586 & site & open air & Middle Paleolithic & Middle Paleolithic \\
\hline 595 & site & open air & Middle Paleolithic & Middle Paleolithic \\
\hline 587 & site & open air & Upper Paleolithic & Upper Paleolithic \\
\hline 578 & site & open air & Upper Paleolithic & \begin{tabular}{|l|} 
Upper Paleolithic \\
\end{tabular} \\
\hline 592 & site & open air & Middle Paleolithic & Middle Paleolithic \\
\hline 588 & site & open air & Middle Paleolithic & Middle Paleolithic \\
\hline 580 & site & open air & Middle Paleolithic & Middle Paleolithic \\
\hline RLS & site & open air & Gravettian & Upper Paleolithic \\
\hline RLS 3 & site & open air & Magdalenian & \begin{tabular}{|l|} 
Upper Paleolithic \\
\end{tabular} \\
\hline Sombrapolis & site & open air & Magdalenian & Upper Paleolithic \\
\hline \begin{tabular}{|l|} 
Way 524 \\
\end{tabular} & site & isolate & Middle Paleolithic & Middle Paleolithic \\
\hline Campo Aventura & site & open air & Magdalenian & Upper Paleolithic \\
\hline Montes 1 & site & open air & Gravettian & \begin{tabular}{|l|} 
Upper Paleolithic \\
\end{tabular} \\
\hline Quebrada dos Cravos & site & open air & Upper Paleolithic & \begin{tabular}{|l|} 
Upper Paleolithic \\
\end{tabular} \\
\hline \begin{tabular}{|l|} 
Quinta dos Bugalhos \\
\end{tabular} & site & open air & Upper Paleolithic & Upper Paleolithic \\
\hline Montes 6 & site & open air & Upper Paleolithic & Upper Paleolithic \\
\hline
\end{tabular}

Table 4.1. Paleolithic localities in Portuguese Estremadura included in this study. 


\subsection{GIS RESULTS}

\section{DISTANCE TO WATER.}

Distance from Paleolithic sites to water is calculated using the "near" geoprocessing function in ArcGIS. This figures a straight-line distance from a site location to the nearest point along the line feature of a drainage channel. The results of this spatial analysis yielded a minimum distance between site-to-water of 5.8 meters; maximum site-to-water distance of 6,105 meters; and a mean distance of 1,274 meters (Figure 4.2).

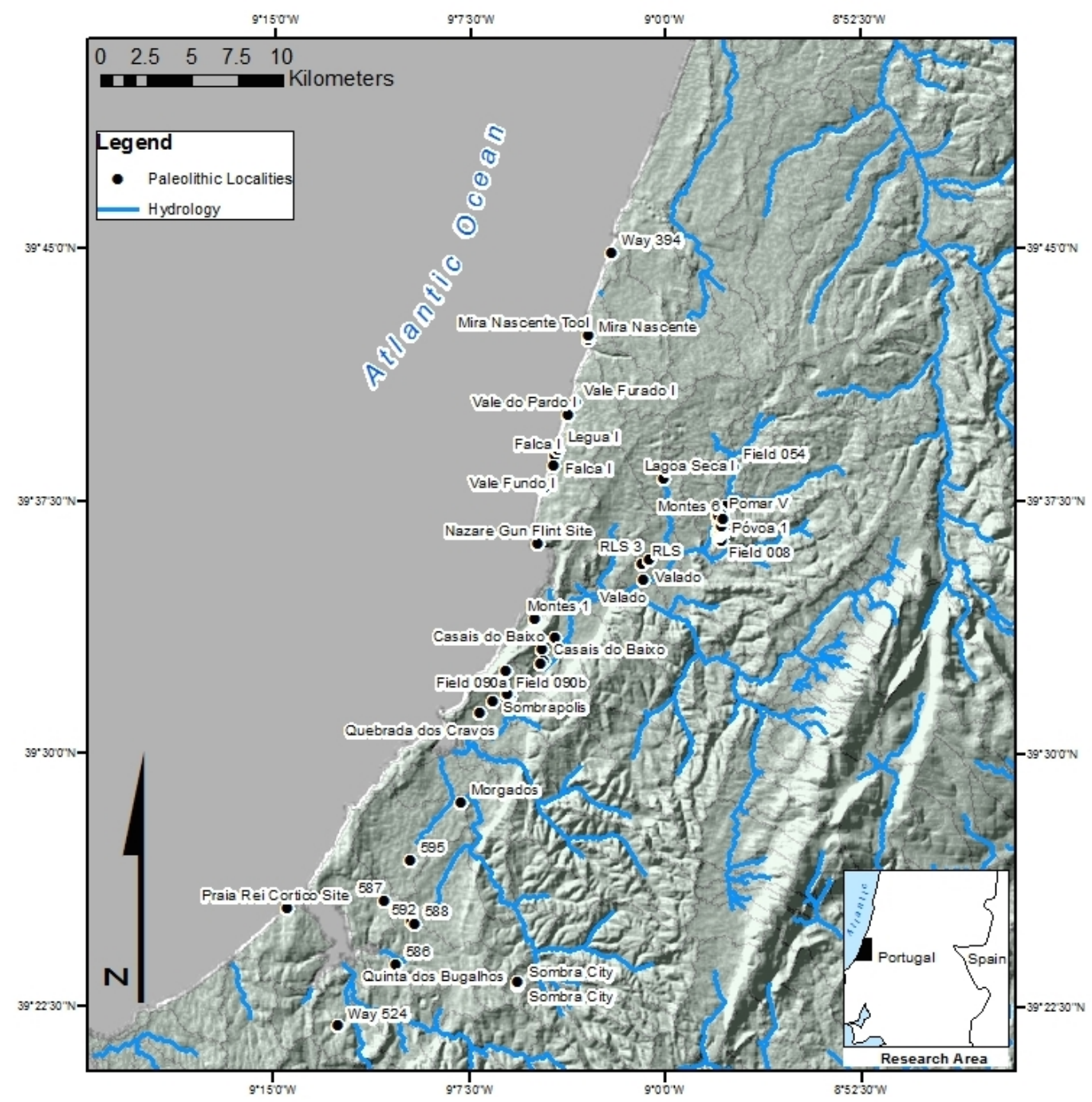

Figure 4.2 Location of Paleolithic Sites in Relation to Water 
Some potential errors to be alert for in this type of analysis include the inability to calculate slope with the method I used, because elevation data is not available for the stream feature class. However, a visual inspection of slope on the hillshaded DEM for the area suggests that no significant terrain obstacles exist between Paleolithic localities and water sources. Another possible source of inaccuracy in measuring distance to water is that the shapefile of stream lines used in the analysis and shown on the map represents modern stream locations, which have likely meandered or, in some cases, been in-filled entirely since the Late Pleistocene (Benedetti et al. 2009). In defense of even severe meander, however, the proximity of these Paleolithic sites to water is such that even hundreds of meters of stream movement would still place most sites within a kilometer of a fresh water source. Another problem with determining stream location or viability of water sources is present in the known down-cutting or incision of streams during the Early Holocene, and the infilling of floodplains, lagoons, and seasonal lakes by recent and historic sediments (Benedetti et al. 2009). To complicate matters further, Garcia (2013) suggests that bathymetric values should be taken into account when considering post-glacial sea level rise. More locally, however, it is argued that tectonic and neotectonic forces are responsible for continental uplift, rather than isostatic rebound (Burke et al. 2011; Benedetti et al. 2009; Cascalheira and Bicho 2013). Consequently, the Pleistocene coastline and littoral zone can only be assessed in approximation when using modern GIS data for Portugal. An additional problem with measuring water is the inability of the line shapefile to weight stream width except in the case of massive rivers (i.e. the Tagus drainage, which lies outside the ASEM coastal research area near modernday Lisbon, Portugal). Despite this minor shortfall regarding data robusticity, all 
Paleolithic sites in question are located in close proximity to first- or second-order streams in the upland headwaters of the coastal watershed systems.

\section{DISTANCE TO CHERT.}

Known chert sources documented through the ASEM project, and past archaeological investigations in the area (Shokler 2002; Thacker 1996) provide point data for this research. Distance from chert sources to Paleolithic localities is calculated by using the "buffer" tool in the geoprocessing toolkit in ArcGIS. The chert outcrops in the study area have a five-kilometer buffer ring placed around them (figure 4.3), to represent a one-hour walking distance, a value established by Burke et al. (2011). A majority of Paleolithic localities in the coastal research area $(\mathrm{n}=45)$ lie within the five-kilometer buffer, making known chert sources within an hour walk to roughly 59.2 percent of these locations. The remaining localities that lie outside the five-kilometer buffer $(n=31)$ are still in relatively close proximity. Some basic statistics of distance to chert are presented in table 4.2 below. Given the generally uniform, and ubiquitous distribution of Paleolithic sites along upland stream drainages, it appears that chert availability plays a role in site distribution. Recent research by Burke et al. (2011) shows a similar trend in distribution of Paleolithic sites associated with chert sources in the Alentejo region of southwestern Portugal, although chert availability is significantly greater in the Estremadura. Site distribution in relation to chert sources does appear to have a correlation, however it is not strong enough to argue for clustering based on this resource alone. More consideration of site correlation with features is presented in the following discussion chapter, as these results are connected to human behavioral factors. 


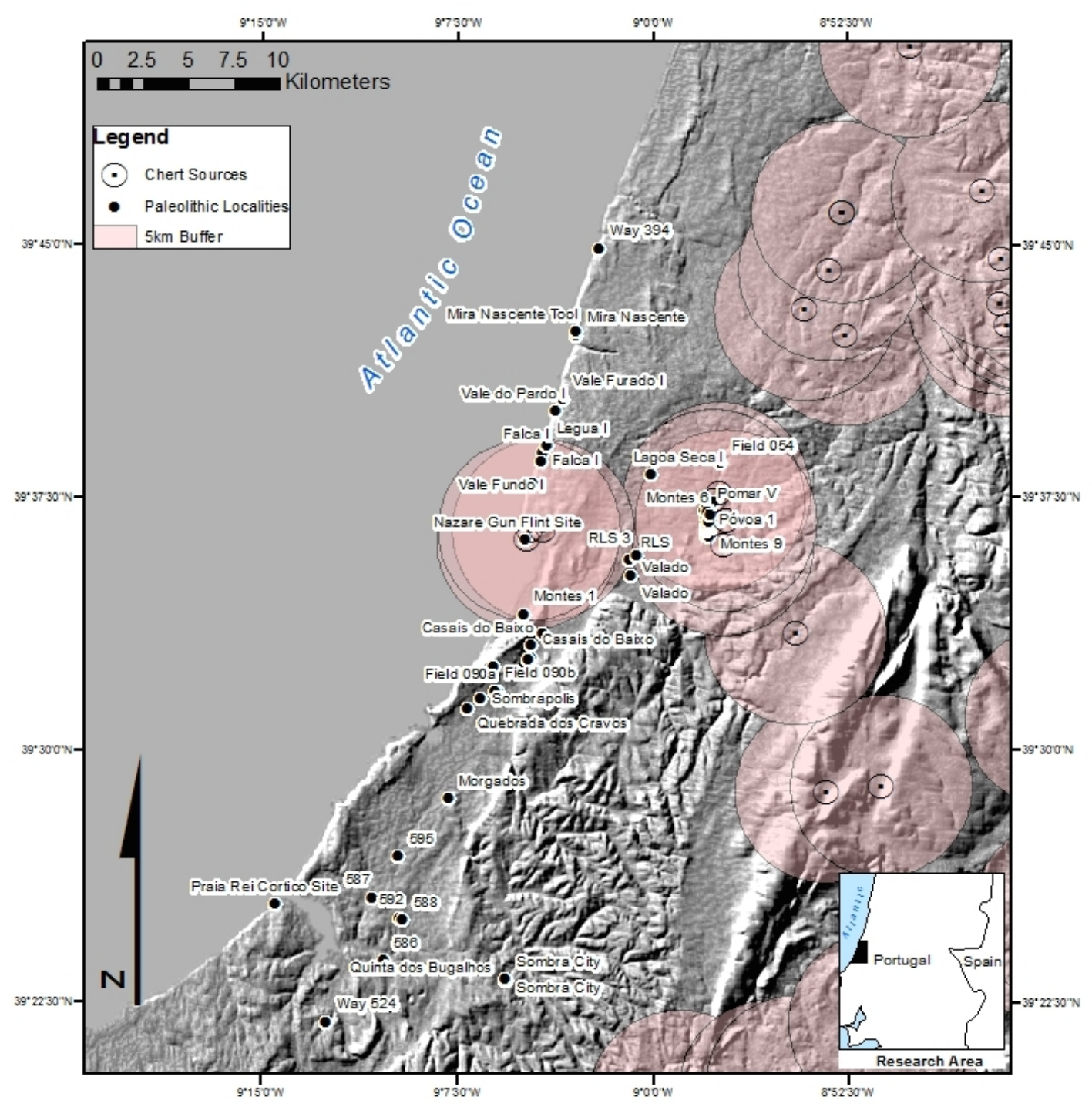

Figure 4.3 Proximity of Paleolithic sites in relation to known chert sources, showing $5 \mathbf{k m}$ buffer.

\section{DISTANCE TO COAST.}

Distance to the coast has been repeatedly identified as an important factor for human adaptation, and is arguably a consistently productive zone for early human adaptation (Burke et al. 2011; Erlandson 2001; Haws et al. 2010; Haws 2012). Distances between marine coastline and Paleolithic sites were calculated by creating a multiple-ring buffer 
around the feature class for the modern coastline. Two buffer-rings were created, showing a five-kilometer distance from the coast, and a 10-kilometer distance from the coast (Figure 4.4). The proximity of Paleolithic localities to the marine coast shows that 100 percent of localities are situated within 10 kilometers of the coastline; and 44.7 percent of Paleolithic localities $(n=34)$ are situated within five kilometers of the coastline. The symbology in the figure below presents Middle Paleolithic and Upper Paleolithic localities differently for a couple reasons: first, some arguments have been presented that a adaptive shifts in response to drastic climate change at the end of the Middle Paleolithic resulted in movement toward the coast (Burke et al. 2011) while others argue that marine ecosystems persist as valuable resource zones of human exploitation (Haws et al. 2010); and second, the graphic is rather cluttered and differentiation between cultural periods adds clarity. The result of this analysis shows that, of the collection of Paleolithic localities, several Middle Paleolithic $(\mathrm{n}=11)$ and Upper Paleolithic $(\mathrm{n}=23)$ locations are situated within five kilometers of the marine coast. More data on distance to coast are presented in the table below. Although this diachronic trend might be used to argue for a shift toward terrestrial resources in the Upper Paleolithic, this sample size is incomplete and the spatial patterning does not conclusively support diachronic trends. The further implications of these results are discussed in greater detail in the following chapter. 


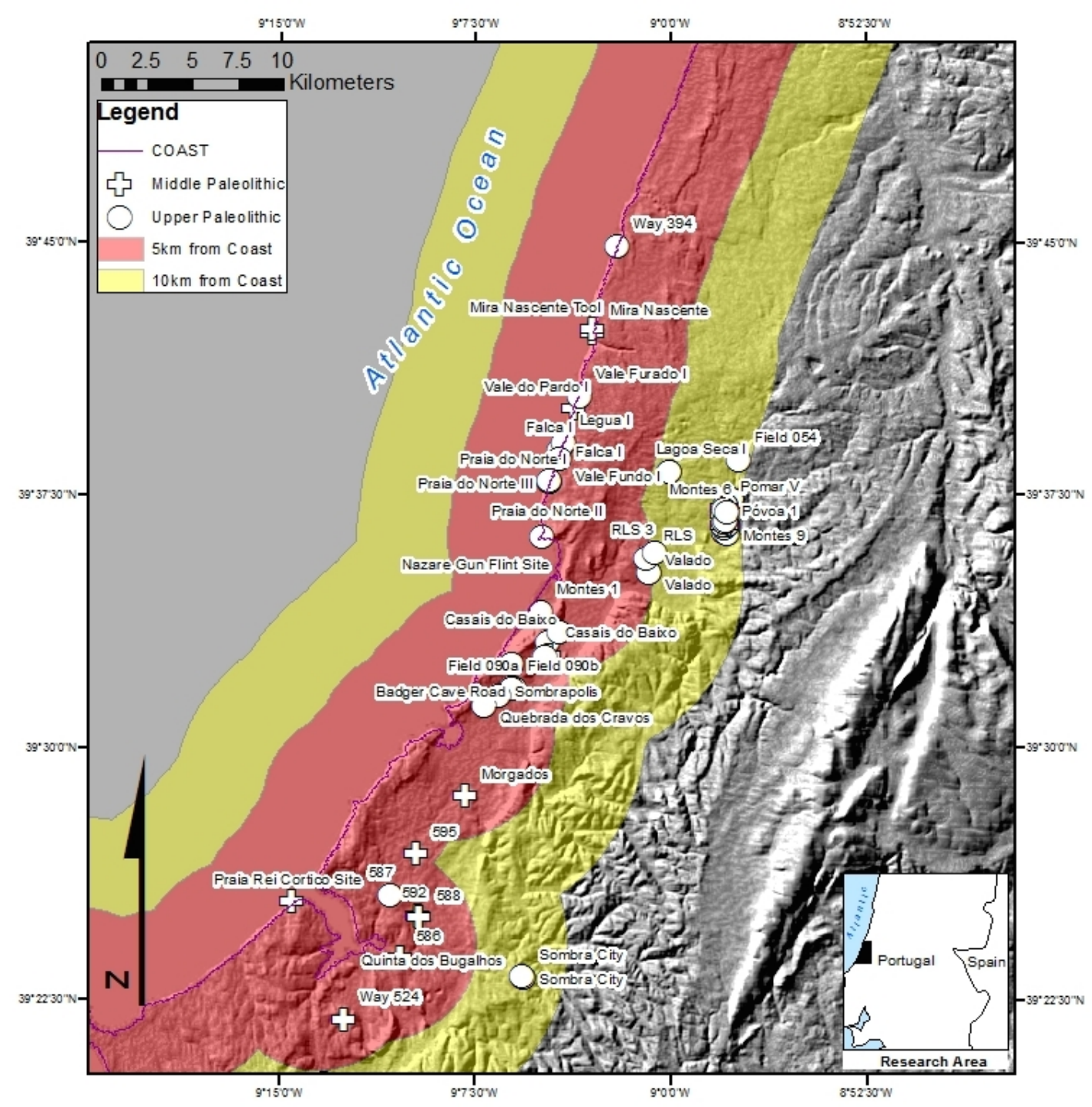

Figure 4.4 Distance from Paleolithic Localities to Marine Coast.

Some potential errors to acknowledge when calculating distance-to-coast for Paleolithic sites emphasize the use of the modern coastline for reference. As with other calculations of Paleolithic features in relation to modern environmental variables, some discrepancies may diminish the efficacy of these explanations. However, Garcia (2013) produced a similar analysis of the Paleolithic in the Cantabria region of Northern Iberia and argued that, in areas of steep bathymetry, the change in horizontal distance may not 
be significant. Similar suggestions have been made for specific areas of steep bathymetry in Portuguese Estremadura, most notably the area surrounding the Paleolithic site of Mira Nascente near the modern town of Nazaré (Benedetti et al. 2009; Haws et al. 2010). Another problem with referencing bathymetry to reconstruct the Paleolithic coastline is the flawed assumption that modern bathymetric elevations directly correlate to prehistoric terrain elevations, rather than being impacted by wave action and tectonic forces.

\begin{tabular}{|r|c|c|c|}
\cline { 2 - 4 } \multicolumn{1}{c|}{} & $\begin{array}{c}\text { Distance to Streams } \\
\text { (meters) }\end{array}$ & $\begin{array}{c}\text { Distance to Chert Sources } \\
\text { (meters) }\end{array}$ & $\begin{array}{c}\text { Distance to Coast } \\
\text { (meters) }\end{array}$ \\
\hline Minimum: & 5.893222 & 90.620086 & 2.417049 \\
\cline { 4 - 5 } Maximum: & 6105.09562 & 18779.14399 & 9651.207503 \\
\hline Mean: & 1274.718571 & 5081.390355 & 5476.38297 \\
\hline $\begin{array}{r}\text { Standard } \\
\text { Deviation: }\end{array}$ & 1572.590987 & & 3899.984882 \\
\hline
\end{tabular}

Table 4.2 Distances from Paleolithic Localities to Sources of Chert, Fresh Water, and Coastline.

\section{INSOLATION.}

Solar insolation on the landscape is argued to be an important factor in understanding paleoenvironmental characteristics (Garcia 2013). Average daily sunlight plays a significant role in determining which flora and fauna will thrive in an area, and therefore impacts habitat fitness in settlement and subsistence dynamics (Garcia 2013). To determine insolation for the ASEM coastal research area, I use a GIS data layer available through IGEOE, upon which I overlay Paleolithic sites (figure 4.5). A simple locational 
analysis that selects for the concurrence of Paleolithic localities and classes of solar insolation confirms that 100 percent of the Paleolithic sites $(n=76)$ in the Estremadura are situated within a range of 2400-2500 average annual hours of sunlight (6.58-6.85 average daily hours). Although this presentation of offers a broad preliminary attempt at explaining relationships between human behavior and environmental factors, it successfully demonstrates some basic trends. Particularly interesting, is the general trend of localities situated upon gently sloping landforms that are more or less south-facing, with some degree of aspect to the east or west. This physical correlation was determined by simple visual inspection in the graphic display of the GIS, though a detailed calculation of overlaps between aspect, slope, and Paleolithic localities can be performed with available geoprocessing tools. The implications for these trends in the co-occurrence of Paleolithic localities with high solar insolation and landforms that are more affected by solar radiation are discussed in the following chapter. 


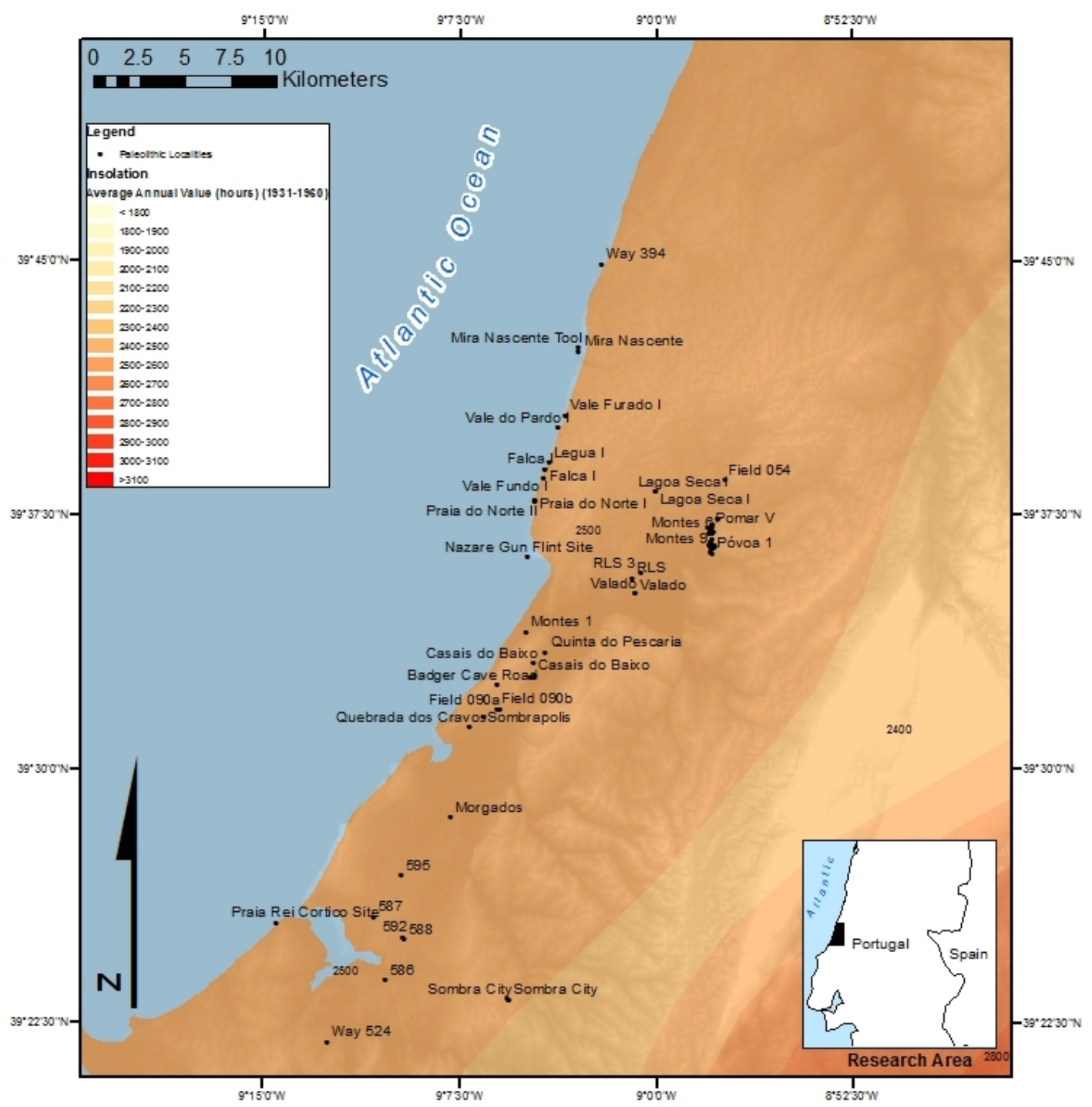

Figure 4.5 Insolation values for coastal research area, showing location of Paleolithic sites.

Some potential errors make this calculation fairly problematic in suggesting paleoenvironmental conditions at Paleolithic localities. First, the data for solar heating and insolation are derived from annual averages gathered from the years 1931-1960, rather than from Paleolithic sites. Another source of inaccuracy is the inability to assess solar conditions on micro-topography at discrete locations due to relatively lowresolution DEM layers. Regardless, the high levels of solar insolation that characterize coastal Estremadura offer yet another link to human adaptation in the region. 


\section{HYPSOMETRY.}

Terrain characteristics are important factors in determining settlement location and habitability of an area. Behavioral ecological models (Kennett 2005; Winterhalder and Kennett 2006), and other GIS analyses of the Paleolithic in Iberia (Burke et al. 2011; Garcia 2013), argue for strong consideration of landform type and degree of slope in cost-benefit strategies of subsistence and movement across the landscape. Hypsometry specifically deals with categories of elevation that comprise catchments, or drainage basins, and related post-depositional factors in archaeological site assemblages (Cohen et al. 2008). This research offers an analysis of hypsometric classes in the Estremadura because strong arguments support the use of hypsometry as one of the relevant methodologies in understanding archaeological site distribution (Cohen et al. 2008). The sedimentation dynamics and geomorphic processes in central Portugal are emphasized by Benedetti et al. (2009), as well as other researchers studying the Paleolithic elsewhere in Portugal (Burke et al. 2011; Cascalheira and Bicho 2013). Additionally, studies of similar site conditions in analogous arid environments have yielded promising results for incorporation of hypsometry in emphasizing geomorphological factors at site and regional levels (Cohen et al. 2008; Fanning et al. 2009; Holdaway and Fanning 2008). These landscape characteristics impact the post-depositional survivability and distribution of Paleolithic localities, and the interpretation of regional patterns in spatial organization.

Burke et al. (2011) argue for the patterning of Paleolithic sites within mid-slope terrain, so to test this I chose a hypsometric data set available through the IGEOE, which presents elevation categories above mean sea level. I overlay Paleolithic sites in the 
coastal research area upon the hypsometric layer (figure 4.6). The results show that all of these sites ( $n=76)$ either lie within 0-50 meters above mean sea level, or within 50-100 meters above mean sea level. The number of sites within the $0-50$ meter category is 33 ; and the number of sites within the $50-100$ meter category is 34 . There are three outlying sites in a higher elevation range (100-200), as well as six localities that do not have hypsometric values available. This appears to reflect arguments presented by Benedetti et al. (2009) regarding geomorphic processes in Estremadura and elsewhere in Portugal (Burke et al. 2011), as well as explanations for the distribution of archaeological material in arid to semi-arid environments at comparable scales of time and space (Cohen et al. 2008; Fanning et al. 2009; Holdaway and Fanning 2008). Further implications of these hypsometric characteristics are discussed in the following chapter. 


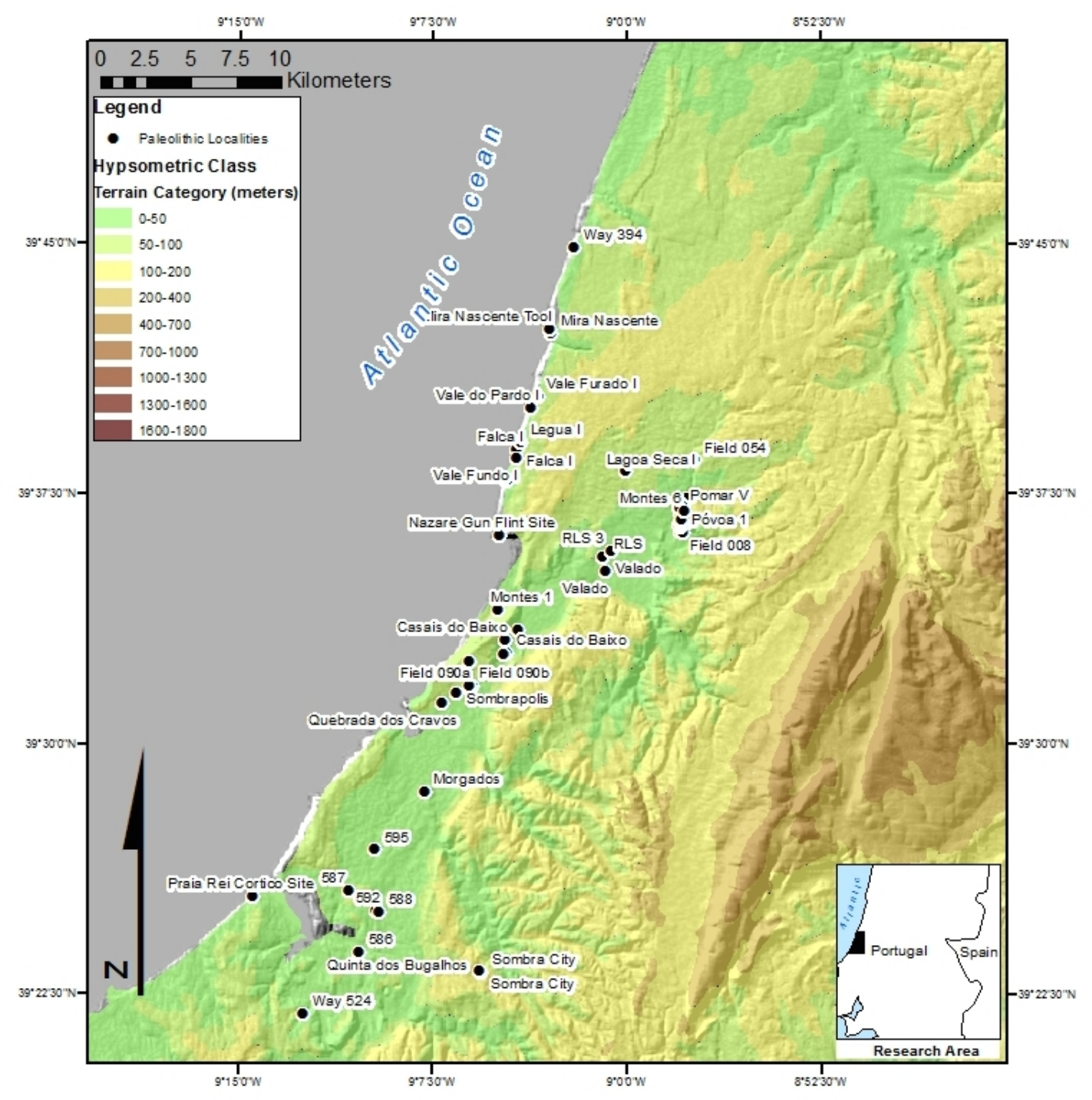

Figure 4.6 Hypsometric values for coastal research area, showing Paleolithic localities.

\section{OTHER CONSIDERATIONS}

As previously mentioned, cost-surface analysis is not performed in this study simply due to software licensing limits. However, this spatial analysis has been a useful tool for several other surveys in providing evidence for behavioralist explanations for movement across a landscape. The absence of cost-surface analysis from this analysis should not be 
a significant limitation, just as the inclusion of such would not be likely to contribute significantly to arguments presented in this research. These data lack attributes such as artifact count, tool manufacture stages, or other information regarding material assemblages, however more complete lithic analyses will significantly expand the data set and add further details for Paleolithic settlement and subsistence behaviors. Similarly, archaeological locations presented in this analysis do not consist of point data that can be weighted by artifact count, nor can I interpolate the areal extent of surface scatters. This limits the accuracy of any measurement on site patterning, as kernel density is absent. The result of such patterning is therefore skewed toward uniform density, which is simply not realistic (Conolly and Lake 2006). Site density according to this data can, at best, be classified as either an isolate or a scatter. Despite this limitation on site-level details, the results of these GIS analyses demonstrate patterns in human behavior and adaptive decision-making on a large scale, and across the entire span of the Paleolithic.

Another analysis that is absent from this research is viewshed. This powerful geoprocessing tool is able to calculate the visible area from a given point. Viewshed analyses are widely used to describe the visual prominence of sites, resources, and other habitat features in relation to each other, and even offer explanations for more abstract qualities such as cosmological significance of landscapes (Conolly and Lake 2006; Wheatley and Gillings 2002). I find these treatments of viewshed to be unconvincing and highly conjectural, given the tendency for its use in defense of "just-so statements" about past behavior and perception of landscape and space (Chamberlain 2008; Hill 2008). Although viewshed may be relevant to behavioralist research questions, the use of viewshed does little in the way of explaining the connection between site distribution and 
settlement and subsistence patterns. A viewshed analysis in this research could certainly say which features are inter-visible within the coastal research area, but visibility characteristics do not offer strong enough explanations within the more utilitarian framework presented above. Applications of viewshed analyses also suffer from the low resolution common to DEM files. While this is not necessarily an issue in larger, landscape-scale studies, the problem of low precision is a limiting factor for viewshed analyses on site-level studies. This can be overcome by detailed surveys with map-quality GPS equipment and a robotic total station (see Holdaway and Fanning 2008), however this may not be possible with the budget or scope of work for many research projects. Future research may benefit from viewshed analyses that include a greater number of archaeological sites, more data on each site, and more detailed knowledge of Paleolithic culture. Before embarking on a task to explain the thought-processes of Paleolithic humans gazing upon a terrain, or the cosmological significance of a viewshed, much more remains to be known. A more thorough discussion on the capacity of GIS analyses to inform the relationship between archaeological site distribution and behavioral dynamics is presented below. 


\section{CHAPTER 5: DISCUSSION}

This chapter discusses the results of the GIS analyses performed in this study, and attempts to place these interpretations within the context of the research goals stated at the outset of this work. The results of each GIS analysis task are briefly discussed on a functional level in the previous chapter, however this chapter provides an interpretation of these results. The sites included $(n=76)$ in GIS analyses include Middle and Upper Paleolithic sites to examine overall adaptive flexibility on a broader scale of time, and over a broader spatial range than a site-level focus. Certainly, much more information on specific techno-cultural complexes is available in the literature at this time, but relatively little of that information is applicable to GIS approaches to the Paleolithic in Portugal. Additionally, high-resolution DEM layers, geologic maps, or soil surveys are not available for much of Portugal, and several of the files used in this study were purchased from the Portuguese military. Additionally, more technologically advanced files, such as LiDAR, deep-scanning satellite (see Gonheim et al. 2012 for an example of applying these types of data to geomorphological reconstruction) are not available for Central Portugal. The environmental conditions and unique landscape characteristics of a study area dictate the type of data that is possible to gather, and furthermore, how it can be effectively interpreted (Wheatley and Gillings 2002). These are some of the primary 
reasons why more sophisticated temporal-spatial studies of the Paleolithic in Portugal have not been performed. Therefore, this analysis may serve as a preliminary point-tofeature approach in applying GIS to understanding the Paleolithic of Central Portugal.

Distance to water is argued to play an important role in site location (Benedetti et al. 2009; Burke et al. 2011; Garcia 2013), however the research presented in this thesis represents one of the first attempts at analyzing this spatial organization in the Estremadura. This GIS analysis reveals close proximity to water as a relatively constant factor in Paleolithic site location. This may confirm HBE arguments for general adaptive flexibility in the exploitation of terrestrial and marine habitats by hunter-gatherers (Erlandson 2001; Kennett 2005). Furthermore, near-coastal freshwater sources would have played important roles in coastal-inland transport of prey and resources, as well as coastward movement (Bicho and Haws 2008; Burke et al. 2011; Cascalheira and Bicho 2013; Haws et al. 2010). The significance of proximity to water may also confirm smallscale, seasonal shifts between coastal and inland resources, as well as longer, millennialscale shifts in habitat range (Cascalheira and Bicho 2013). Additionally, the location of Paleolithic sites primarily along second-order ranked streams (as confirmed by the Strahler stream-order designations in the attribute tables available for the stream shapefile) may suggest the long-term significance of these water features, as climate fluctuations and changes in mean sea level during the Middle and Upper Paleolithic would have differentially impacted lower-elevation, high-ranked streams, and upperelevation, lower ranked streams (Benedetti et al. 2009; Burke et al. 2011). This suggestion may not have a strong relationship with the long-term development of drainages (even recent Holocene channels), nor with long-term behavioral patterns, as the 
location of some Paleolithic sites along first-order upland streams may indicate. A mean site-to-water distance of 1,274 meters from is not terribly surprising considering the extensive drainage network that characterizes the study area. However, the local geomorphology adds a complex twist; as hydrologic and sedimentary processes that began during the Late Pleistocene continued to shape the local hydrology and fill valleys with eroding sediments from upland landforms during the Holocene (Benedetti et al. 2009). Other research also suggests a great deal of transformation to the landscape has occurred since the LGM (Bicho and Haws 2008; Burke et al. 2011; Cascalheira and Bicho 2013). For this reason distance-to-water alone is not a sufficient indicator of human behavior. Other tests are necessary to connect spatial distribution of Paleolithic material to evidence of settlement and subsistence strategies.

Proximity to chert resources is almost unanimously indicated as a selective factor in habitat suitability (Barton et al. 2002; Burke et al. 2011; Cascalheira and Bicho 2013; Shokler 2002; Thacker 1996). A significant number of Paleolithic localities ( $\mathrm{n}=34 ; 44.7 \%$ of total) in the research area are located within a five-kilometer radius of known chert outcrops, and the remaining Paleolithic locations are in relatively close proximity with a mean distance to chert of 5,081 meters and maximum distance of 18,779 meters.

The data presented above for spatial organization in relation to chert facilitates a discussion of behavioral complexity in human-ecosystem interaction. These spatial relationships confirm arguments for the preference of sites within approximately a onehour walk to lithic resources (Burke et al. 2011). The Paleolithic localities situated outside the five-kilometer radius of chert sources are still predominately located within 10 kilometers; a distance that Burke et al. (2011) argue retains a net return in the cost of 
procuring material for the manufacture of tools. The distance from a Paleolithic location to a chert source is relevant to HBE models of energy maximization and time minimization in stone tool economies (Kennett 2005; Shokler 2002; Thacker 1996; Winterhalder and Kennett 2006). Proximity to lithic resources is expected to play an increasingly important role toward the Upper Paleolithic, as ecological contexts changed due to increases in population and other environmental pressures, and tool diversification and resource intensification are visible in the archaeological record (Bicho and Haws 2008; Cascalheira and Bicho 2013; Haws et al. 2012; Shokler 2002; Thacker 1996). Some researchers argue that increased pressure on chert and flint resources during the Upper Paleolithic may explain increasing frequencies of other materials such as quartz and quartzite in Upper Paleolithic assemblages (Bicho and Haws 2008; Burke et al. 2011; Shokler 2002; Thacker 1996). As a preliminary spatial analysis, this research shows potential to gain further knowledge about Paleolithic subsistence and land-use through more thorough studies on lithic assemblages.

Distance to coast has been identified as an important variable of consideration for Paleolithic localities in Estremadura (Bicho and Haws 2008; Haws et al. 2010; Haws 2012). This variable is important because of the implications for conceptual models such as diet-breadth, resource intensification, and settlement responses to population pressure. Results from site-level investigations indicate increased populations during the Upper Paleolithic (Cascalheira and Bicho 2013; Haws et al. 2010; Haws 2012; Thacker 1996). HBE models for population pressures argue increases in population are indicated by uniformity in dispersal due to increased competition for resource patches (Hodder and Orton 1976). The overall uniform patterning of Paleolithic localities in relation to the 
marine coastline is also explained by the despotic distribution model, which further indicates responses to population pressures on the ecosystem (Kennett 2005; Winterhalder and Kennett 2006). Additionally, distance to coast is important when considering responses to drastic climate fluctuations during the Middle and Upper Paleolithic (Bicho and Haws 2008; Haws 2012). A higher number of Upper Paleolithic localities within five kilometers may reflect site-level explanations for greater productivity among marine resources resulting from a colder, drier climate (Bicho and Haws 2008; Cascalheira and Bicho 2013; Haws et al. 2010; Haws 2012). These environmental conditions resulted loss of vegetation due to increased aridity (Benedetti et al. 2009; Cascalheira and Bicho 2013) and possibly diminished return rates for terrestrial prey (Haws et al. 2010). The measurement of distance to coast in this research supports general arguments for human exploitation of marine resources, in addition to supporting explanations for intensification of resources and increases in human populations toward the Upper Paleolithic (Haws et al. 2010; Haws 2012).

Solar insolation has been argued to play a role in settlement and subsistence patterns (Garcia 2013). Similar to other GIS approaches to reconstructing solar insolation for the Iberian Paleolithic (Garcia 2013), this research references modern topography and solar values. I use modern insolation values to test this relationship, but I do not place a strong emphasis on its effectiveness to explain behavioral patterns. Solar impact during the Paleolithic would have played a role in vegetation patterns and terrestrial prey availabilty, but there are other climate proxy data available that more accurately measure these relationships. As presented in the previous chapter, the results show a complete correlation between Paleolithic sites and solar insolation values between 2400 and 2500 
average annual hours of sunlight (6.58-6.85 average daily hours). However, these values are relatively uniformly distributed throughout the rest of Portugal, so a correlation between site location and this range of solar insolation should not imply a causal relationship. A more telling interpretation of these results for solar insolation is that 100 percent of Paleolithic localities exist within a range of 2400-2500 average annual hours of sunlight (6.58-6.85 average daily hours), and the landforms upon which these localities are situated are also more receptive to solar radiation. This trend in topographic setting, although not yet analyzed beyond visual inspection on the DEM, provides another landscape-scale pattern in the spatial organization of Paleolithic localities. The situation of a locality on a landform in relation to sun exposure may be a site-level indicator of human decision-making processes in identifying productive environments (Garcia 2013).

This research also tests the relationship between site location and hypsometry for the study area. The results of hypsometric testing may be more informative for site preservation and visibility than for human behavior, due to the focus on large-scale fluvial activity on landscapes (Cohen et al. 2008). Rather than perform a detailed geomorphological analysis of each landform setting at Paleolithic localities, an analysis of hypsometric class is a relatively quick way to gain a broad understanding of general landform classes based on slope and drainage potential. The results of this analysis conform to descriptions of Paleolithic site locations in other study areas throughout Portugal, in which sites tend to be situated in gently sloping uplands in the middle of drainage catchments (Benedetti et al. 2009; Burke et al. 2011; Bicho and Haws 2008). Additionally, these findings offer a preliminary confirmation of distribution patterns generally suggested for Pleistocene-age deposits in arid environments (Fanning et al. 
2009; Holdaway and Fanning 2008). This may suggest the potential to gain further understanding of site distributions, depositional patterns, and long-term post-depositional processes from future geomorphological investigations. One weakness of the hypsometric correlation used in this research, however, is that the coverage of the hypsometry layer considers a broad, regional scale. This scope of observation has been cautioned against by some because it fails to account for site-level micromorphology and micro-terrain, and also cannot account for patchiness or heterogeneity in soil distribution (Cohen et al. 2008). Nonetheless, this introductory application of hypsometry to landscape-scale distributions succeeds in demonstrating trends in landform characteristics that bear implications for the visibility of archaeological surfaces in Portuguese Estremadura.

Overall, GIS analyses on the assemblage of Paleolithic sites in this study provide supporting evidence for landscape-scale trends in human behavior. Overall spatial organization for Paleolithic localities support evidence for the BSR at the end of the Middle Paleolithic (Bicho and Haws 2008; Cascalheira and Bicho 2013; Haws 2003; Haws et al. 2010). The near-coastal location, proximity to water and lithic resources, mid-level terrain preference, and generally good solar insolation are factors that indicate optimal habitat conditions during glacial interstadial conditions. Similarly, marine transgressions during interstadial periods leading into the Upper Paleolithic would have likely had less impact on these site characteristics; as some argue near-coastal locations on dissected uplands serve as refugia during these times (Benedetti et al. 2009; Bicho and Haws 2008; Burke et al. 2011; Cascalheira and Bicho 2013). The spatial relationships in the Estremadura region presented in this work provide explanations for landscape-scale behavioral patterns. Additionally, these results support behavioral trends observed in site- 
level investigations (Cascalheira and Bicho 2013; Haws et al. 2010; Haws 2012).

Additionally, landscape-scale spatial analyses offer potential to gain further knowledge of human behavioral patterns during severe climate fluctuations at the LGM.

In the second chapter of this thesis, I presented a background of archaeological contexts for Paleolithic Portugal that raised concerns about the efficacy of performing spatial analyses without explicit theoretical and methodological guidance throughout a study. This discussion comes back to this because several relevant acknowledgements must be made from the results of this research. First, the author's involvement in the ASEM project is fairly transient due to the short duration of graduate thesis research. Second, other researchers collected the data sets used in this thesis with other priorities in their scopes of work. The data recorded was formatted to match previous collection methods, not to 'reinvent the wheel' so to speak. The theoretical perspectives applied throughout this project has been formed by consulting literature on HBE, landscape, resilience, and Panarchy - all of which are referenced to varying degrees in archaeological investigations of the Paleolithic in Portugal (Barton et al. 2013; Bicho and Haws 2012; Haws 2012a, 2012b). This has shaped the research design of this thesis by focusing on testable variables that might present spatial evidence for landscape-scale human-ecosystem interaction. The following chapter presents concluding remarks on the results of this data and their relevance for connecting spatial distribution to evidence of human behavior. 


\section{CHAPTER 6: CONCLUSIONS}

\subsection{ARCHAEOLOGICAL CONCLUSIONS}

This research connects larger, landscape-level patterns with trends in human behavior that are visible on site-level scales. This section addresses theoretical and methodological conclusions on the interpretations presented above. It is difficult to fully assess diachronic trends relating to concepts of Panarchy and resilience; and the discussion of GIS support for a landscape approach in Estremadura is unfortunately incomplete. The difficulty in supporting landscape approaches with this data centers largely on the nature of archaeological deposits and post-depositional forces in Estremadura. The point data for archaeological locations represents a palimpsest of material culture accumulating on landscape surfaces over tens of thousands of years. These ephemeral, mixed-component lithic scatters sometimes contain Middle Paleolithic and Upper Paleolithic technology, as well as non-diagnostic material of unknown temporal and cultural affiliation. Recent archaeological investigations at the Paleolithic localities of Lagoa Seca, Ribeiras Lagoa Seca, and Sombrapolis in 2013 (unpublished) yielded little subsurface potential despite dense surface concentrations of diagnostic lithic material. Figure 6.1 shows an overview photograph of the Middle Paleolithic site, Lagoa Seca, in which land-use has significantly 
impacted the integrity of archaeological deposits. This research includes these Paleolithic localities, yet the data cannot offer support for landscape approaches when considered on a broader level. Although site-level studies in Estremadura have successfully demonstrated deep diachronic trends through OSL and radiometric carbon dating (Benedetti et al. 2009; Cascalheira and Bicho 2013; Haws et al. 2010), a broader approach using open-air localities does not have the same effect.

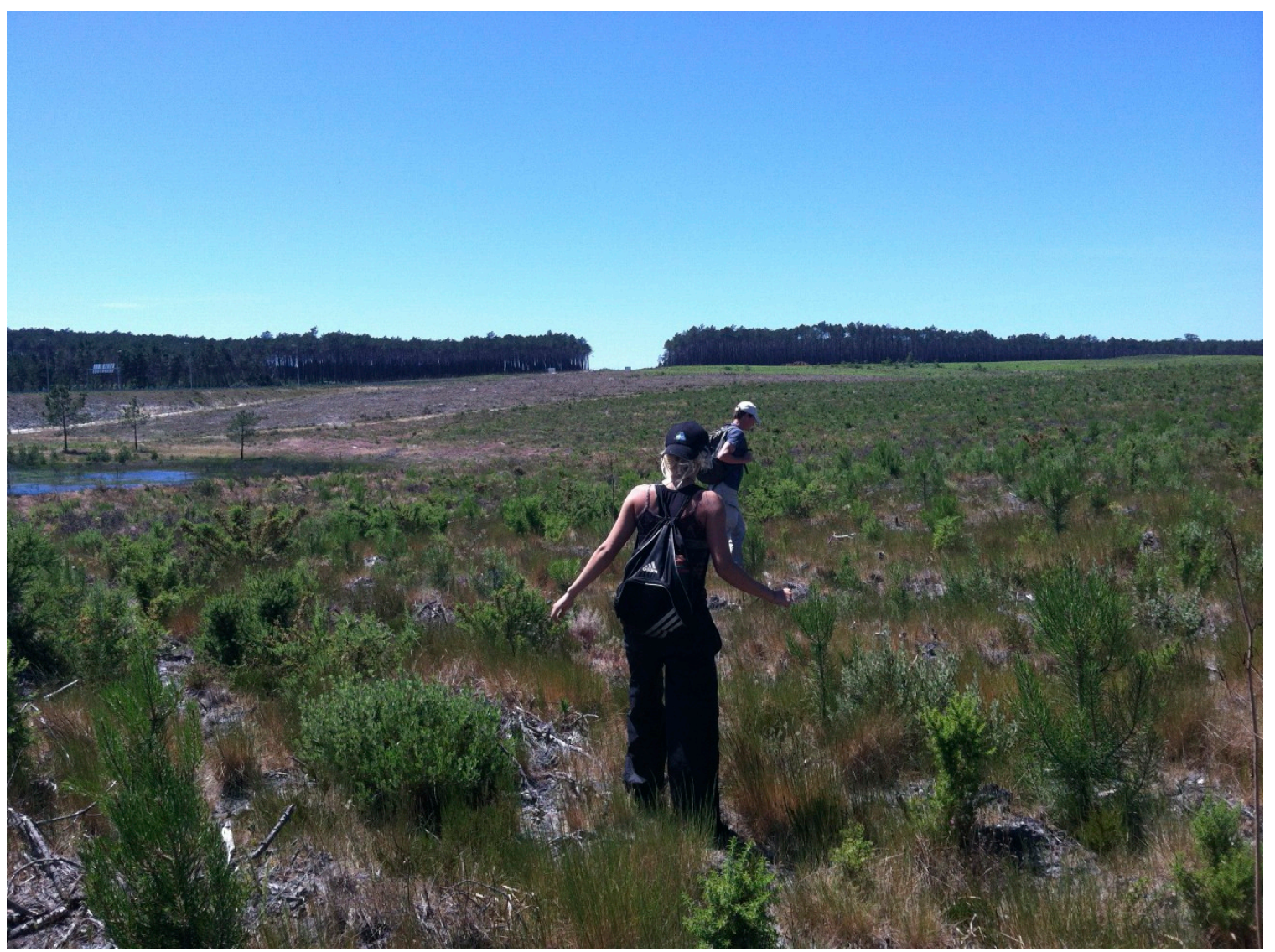

Figure 6.1 Overview of Middle Paleolithic site, Lagoa Seca, facing northwest.

The interpretations drawn from the GIS analyses above do, however, strongly support some of the theoretical models proposed by HBE. The confirmation of Central Place Foraging models by the close proximity of Paleolithic localities to sources of chert and fresh water suggests that these localities represent adaptive habitats. Also related to the spatial organization of these Paleolithic localities is a concern for cost-benefit strategies 
that are embedded within HBE models (Winterhalder and Kennett 2006). Clustering of sites indicates patchiness in the distribution of prey and resources, as well as demonstrating competitive fitness and temporality of occupation (Hodder and Orton 1976). The close proximity of localities to chert sources may have offered Paleolithic hunter-gatherers relatively high returns on time and energy spent on acquiring and manufacturing stone tools if hunting strategies and diet-breadth were optimized through tool-use. Thacker (1996) emphasizes the importance of distance to chert (flint) in tool use and resource intensification. Research on habitat location shows that clustered patterns of localities according to beneficial resources indicates choice. However, the data presented here is inconclusive in determining overall site patterning. When the shift between terrestrial and marine resources (especially during the Upper Paleolithic) is considered, distance to coast becomes an important variable in habitat location. A somewhat surprising result, then, is that there seems to be uniformity in distribution of localities in relation to the modern coastline, even diachronically between Middle and Upper Paleolithic localities. As discussed above, this uniformity may reflect sampling bias but it also supports conceptual models for settlement strategy in response to population pressures. Another reason that spatial patterning is important in regard to HBE is that the uniform patterning of Paleolithic localities may reflect pressures from human population and interaction with the environment. Hodder and Orton describe these spatial conditions in the analysis of archaeology data by explaining that, "in time, increased population may lead to increased site density, greater competition between sites for land, and therefore greater uniformity in spacing (1976: 73). Although the data presented in this research offers only an initial attempt at understanding these spatial relationships, this patterning 
supports HBE models for settlement patterns and may be of interest for future research. The research presented here builds upon understandings of Paleolithic behavior by connecting landscape-scale patterns to from site-level trends.

Finally, this study contributes a basic understanding to the impact of post-depositional forces on the distribution of archaeological material. The use of hypsometry to explain the spatial organization of Paleolithic localities links broader regional trends to the finergrained geomorphological studies conducted at specific sites (Benedetti et al. 2009; Haws et al. 2010; Haws 2012). The correlation of Paleolithic sites within moderate hypsometric ranges over a broad scale on the landscape adds a discrete variable to otherwise patchy distribution of archaeological surfaces. This relatively new methodology in studying post-depositional impacts to surface sites is particularly adept at considering catchment-level dynamics in relation to archaeological contexts (Cohen et al. 2008). Although the application of hypsometry in this study is rather basic, it provides yet another link to understanding the patterning of Paleolithic localities in the Estremadura.

\subsection{GIS CONCLUSIONS}

Despite the small sample size of data on Paleolithic localities, , this research successfully demonstrates landscape-scale support for site-level behavioral patterns through simple spatial analyses. Overall, the results of the GIS analysis presented above highlight the importance of understanding human adaptations to the environment during the Paleolithic. Of specific interest is the correlation between overall high levels of solar insolation, generally south-facing landforms, and site location. This non-random implication for human behavior provides a link to conceptual models offered by HBE for 
habitat choice. Further implications for habitat choice and spatial patterning of behavior are visible in the close proximity of Paleolithic localities to sources of fresh water and chert outcrops. As discussed in the previous chapter, this is another example of nonrandom spatial patterning in sites that demonstrates human decision-making on a landscape scale. The cost of travel to chert sources, and the need for fresh water confirm conceptual models about human subsistence and interaction with the environment. Furthermore, this landscape-level trend of closeness to chert sources reinforces site-level observations about tool forms and intensification in resource-use strategies. Another important result of a landscape approach to using GIS on the Paleolithic sites in study is that site locations and habitat types generally remain uniform throughout the Middle Paleolithic and Upper Paleolithic. While this result may reflect other factors concerning the data itself, it generally supports behavioral concepts like the broad-spectrum revolution and diet-breadth. This patterning of archaeological localities also highlights the importance of the Estremadura as an adaptive environment, with chert sources and environmental features that led to the fluorescence of human populations (Haws 2012; Shokler 2002; Thacker 1996) and sustained human activity throughout wildly changing climactic conditions (Benedetti et al. 2009; Cascalheira and Bicho 2013; Haws et al. 2010; Haws 2012). The presentation of hypsometry in this research adds a different variable to the spatial patterning of Paleolithic localities. Rather than offering correlations with human behavior, the patterning of sites within broad hypsometric classes is indicative of landscape-scale post-depositional forces. The general occurrence of Paleolithic localities in areas of low-to-moderate slope in upland landforms reinforces the emphasis this research places on understanding the palimpsest of material culture visible 
in the Paleolithic record. The use of hypsometry in this research offers an incomplete analysis of site deposition, however contributes a preliminary effort to connect landscapescale patterns to site-level understandings of geomorphological factors. The use of hypsometry in studying archaeological areas also shows potential for further enhancing methodology in complicated depositional contexts (Cohen et al. 2008).

The introductory chapter of this research outlined a debate within GIS applications, as to whether GIS is merely a tool or if it is a science in its own right (Wheatley and Gillings 2002). The utilitarian aspect of GIS is immediately visible in the methods and results of this thesis; GPS data was collected in the field, along with additional details for each spatial reference, stored in a GIS, and visualized through modeling and mapping. The theoretical guidance of the entire scope of research - from field investigations, data collection, GIS analysis, and interpretation - lends weight to the argument for GIS as a science. Although perhaps not a science in its own regard, considered apart from the things a GIS is used to study, a GIS is connected to and implicated within the study of human behavior and adaptations to changing environments. GIS makes it possible to study diachronic spatial relationships of localities of Paleolithic human behavior, in relation to water, lithic resources, and environmental factors. The power of GIS in forming explanations for behavioral trends during the Paleolithic comes from a theoryladen methodology in sampling and analyzing data. This thesis demonstrates that by interpreting spatial data within the conceptual workings of HBE, thereby integrating GIS as one of many components in that theoretical approach. It is difficult, then, to consider GIS as merely a tool that is separate from the product of its use, just as it is difficult to consider a theoretical approach as something existing purely in a vacuum apart from 
implications for human behavior and understandings of material culture. Applications of GIS in archaeology, just as in this research, integrate the tools and methods of geospatial analysis within the scientific discipline in a way that involves the use of all modes of explanation. 


\section{REFERENCES}

Angelucci, Diego E, and João Zilhão.

2009. Stratigraphy and Formation Processes of the Upper Pleistocene Deposit at Gruta da Oliveira, Almonda Karstic System, Torres Novas, Portugal. GEA Geoarchaeology 24 (3): $277-310$.

Barton, C. Michael, et al..

2002. Dynamic Landscapes, Artifact Taphonomy, and Landuse Modeling in the Western Mediterranean. Geoarchaeology: An International Journal. 17(2): 155-190.

Benedetti, M.M., et al..

2009. Late Pleistocene raised beaches of coastal Estremadura, central Portugal. Quaternary Science Reviews 28: 3428-3447.

Bicho, Nuno Ferreira.

1994. The End of the Paleolithic and Mesolithic in Portugal. Current Anthropology. 35(5): 664-674. 
Bicho, Nuno Ferreira.

2009. On the Edge: Early Holocene Adaptations in Southwestern Iberia. Journal of Anthropological Research. 65(2): 185-206.

Bicho, Nuno, et al..

2006. Two sides of the same coin - rocks, bones and site function of Picareiro Cave, central Portugal. Journal of Anthropological Archaeology. 25: 485-499.

Bicho, Nuno and Jonathan Haws

2008. At the land's end: Marine resources and the importance of fluctuations in the coastline in the prehistoric hunter-gatherer economy of Portugal. Quaternary Science Reviews. 27: 2166-2175.

Bicho, Nuno, and Jonathan Haws

2012a. The Magdalenian in Central and Southern Portugal: Human Ecology at the End of the Pleistocene. Quaternary International 272-273: 6-16.

2012b. The Magdalenian in Central and Southern Portugal: Human Ecology at the End of the Pleistocene. Quaternary International 272-273: 6-16.

Burke, Ariane. et al..

2011. The Paleolithic occupation of southern Alentejo: the Sado River Drainage Survey. Trabajos de Prehistoria. 68(1): 25-49.

Cascalheira, João. and Nuno Bicho

2013. Hunter-gatherer ecodynamics and the impact of the Heinrich event 2 in Central and Southern Portugal. Quaternary International. 318: 117-127. 
Chamberlain, Andrew.

2008. Pre-Homo sapiens Place-Worlds. In Handbook of Landscape Archaeology. Bruno David and Julian Thomas, eds. Walnut Creek: Left Coast Press. (Pp. 102-108).

Cohen, Sagy. et al..

2008. A methodology for calculating the spatial distribution of the area-slope equation and the hypsometric integral within a catchment. Journal of Geophysical Research. 113: 1-13.

Conolly, James. And Mark Lake.

2006. Geographical Information Systems in Archaeology. Cambridge: Cambridge University Press.

David, Bruno. And Julian Thomas.

2008. Landscape Archaeology: Introduction. In Handbook of Landscape Archaeology. Bruno David and Julian Thomas, eds. Walnut Creek: Left Coast Press. (Pp. 2743).

Erlandson, Jon M.

2001. The Archaeology of Aquatic Adaptations: Paradigms for a New Millennium. Journal of Archaeological Research. 9(4): 287-350.

Fanning, Patricia C. et al..

2009. The Surface Archaeological Record in Arid Australia: Geomorphic Controls on Preservation, Exposure, and Visibility. Geoarchaeology: An International Journal. 24(2): 121-146. 
Fish, Suzanne K. and Stephen A. Kowalewski.

1990. The Archaeology of Regions. Washington, D.C.: Smithsonian Institution.

Garcia, Alejandro.

2013. GIS-based Methodology for Paleolithic Site Location Preferences Analysis: A Case Study from Late Palaelolithic Cantabria (Northern Iberian Peninsula). Journal of Archaeological Science. 40: 217-226.

Graham, Russel et al...

1998. Pleistocene Extinctions: Chronology, Non-analog Communities, and Environmental Change. Paper presented at the American Museum of Natural History Seminar Series, 1998.

Haws, Jonathan A. et al..

2010a. Coastal Wetlands and the Neanderthal Settlement of Portuguese Estremadura. Geoarchaeology: An International Journal. 25(6): 709-744.

2010b. Paleolithic Landscapes and Seascapes of the West Coast of Portugal. In Trekking the Shore: Changing Coastlines and the Antiquity of Coastal Settlement. Nuno F. Bicho, Jonathan A. Haws, and Loren G. Davis, eds. New York: Springer. (203246).

2012. Paleolithic Socionatural Relationships During MIS 3 and 2 in Central Portugal. Quaternary International 264: 61-77. 
Hill, Russell A.

2008. Nonhuman Primate Approaches to Landscapes. In Handbook of Landscape Archaeology. Bruno David and Julian Thomas, eds. Walnut Creek: Left Coast Press. (Pp. 95-101).

Hockett, Bryan.

2002. Advances in Paleolithic Archaeology: An Introduction. Journal of Archaeological Method and Theory. 9(2): 97-100.

Hockett, Bryan. And Jonathan A. Haws.

2002. Taphonomic and Methodological Perspectives of Leoporid Hunting During the Upper Paleolithic of the Western Mediterranean Basin. Journal of Archaeological Method and Theory. 9(3): 269-302.

2009. Continuity in animal resource diversity in the Upper Paleolithic diet of central Portugal. Before Farming. 2009: 1-14.

Hodder, Ian. And Clive Orton.

1979. Spatial Analysis in Archaeology. Cambridge: Cambridge University Press.

Holling, C.S. and L.H. Gunderson.

2002. Resilience and Adaptive Cycles. In Panarchy: Understanding Transformations in Human and Natural Systems. C.S. Holling and L.H. Gunderson, eds. Pp. 25-62. Washington, D.C.: Island Press. 
Holdaway, Simon. And Patricia Fanning.

2008. Developing a Landscape History as Part of a Survey Strategy: A Critique of Current Settlement System Approaches Based on Case Studies from Western New South Wales, Australia. Journal of Archaeological Method and Theory. 15: 167-189.

Holton, Kimberly DaCosta

2005. Performing Folklore: Ranchos Folclóricos from Lisbon to Newark. Bloomington: Indiana University Press.

Howard, Phil.

2007. Archaeology Surveying and Mapping: Recording and Depicting the Landscape. London: Taylor and Francis.

Kennett, Douglas

2005. The Island Chumash: Human Behavioral Ecology of a Maritime Society. Berkeley: University of California Press.

Maxwell, Joseph A.

1996. Qualitative Research Design: An Interactive Approach. Thousand Oaks: Sage Publications.

Morrow, Toby A.

1996. Bigger is Better: Comments on Kuhn's Formal Approach to Mobile Tool Kits. American Antiquity. 61(3): 581-590.

Redman, Charles L.

1999. Human Impact on Ancient Environments. The University of Arizona Press 
Robbins, Paul.

2004. Destruction of Nature: Human Impact and Environmental Degradation. In Political Ecology: A Critical Introduction. Paul Robbins, ed. Pp. 87-106. Hoboken: Wiley Publishing.

Santonja, Manuel and Paola Villa.

1990. The Lower Paleolithic of Spain and Portugal. Journal of World Prehistory. 4(1): 45-94.

Schiffer, Michael B., Alan P. Sullivan, and Timothy C. Klinger

1978. The Design of Archaeological Surveys. World Archaeology 10(1): 1-28.

Schiffer, Michael B., and James M. Skibo

2008. People and Things: A Behavioral Approach to Material Culture. New York: Springer.

Shokler, Jeffrey E.

2002. Approaches to the sourcing of flint in archaeological contexts: results of research from Portuguese Estremadura. In Asmosia 5: Interdisciplinary Studies on Ancient Stone. JJ Hermann, Jr. et al., eds. Pp. 176-187. London: Archetype Publications.

Thacker, Paul

1996. Hunter-Gatherer Lithic Economy and Settlement Systems: Understanding Regional Assemblage Variability in the Upper Paleolithic of Portuguese Estremadura. In Stone Tools: Theoretical Insights into Human Prehistory. George H. Odell, ed. Pp. 101-124. New York: Plenum Press. 
Trinkaus, Erik, Maki, Julia, Zilhão, João

2007. Middle Paleolithic human remains from the Gruta da Oliveira (Torres Novas), Portugal. AJPA American Journal of Physical Anthropology 134(2): 263-273.

Turrero, Pablo. et al..

2013. The spatial distribution of Palaeolithic human settlements and its influence on palaeoecological studies: a case from Northern Iberia. Journal of Archaeological Science. 40: 4127-4138.

van der Leeuw, Sander. and Charles L. Redman

2002. Placing Archaeology at the Center of Socio-Natural Studies. American Antiquity. 67(4): 597-605.

Wheatley, David. And Mark Gillings.

2002. Spatial Technology and Archaeology: The Archaeological Applications of GIS. London: Taylor and Francis.

White, Gregory G. and Thomas F. King.

2007. The Archaeological Survey Manual. Walnut Creek: Left Coast Press.

Willman, John C. et al..

2012. Middle Paleolithic human remains from the Gruta Da Oliveira (Torres Novas), Portugal. AJPA American Journal of Physical Anthropology 149(1): 39-51. 
Winterhalder, Bruce and Douglas J. Kennett

2006. Behavioral Ecology and the Transition from Hunting and Gathering to Agriculture.

Douglas Kennett and Bruce Winterhalder, eds. Pp. 41-62. Berkeley: University of California Press. 


\section{CURRICULUM VITAE}

502.645 .3116

chrissims@brockington.org

\section{Christopher M. Sims}

\section{Position}

Experience
Archaeology Project Manager

2012-present University of Louisville, Louisville, KY

\section{Sustainability Project Manager}

- Organize and market campus-wide sustainability events and projects, one of which being the nationally-recognized "Earna-Bike" voucher program, the first of its kind.

- Coordinate with university administration and business personnel on sustainable operation of university facilities.

- Manage volunteer interns and develop intern projects.

2009-to present

\section{Archaeologist (A3), Crew Chief}

- Planned and executed field investigations, conducted documentation and data collection, prepared technical reports, and supervised field personnel.

- Worked on wide range of prehistoric and historic sites in seven states.

- Completed fieldwork and prepared reports under Section 106 and 110, ARRA guidelines.

\section{Director of Survey and Reconnaissance}

- Planned and executed pedestrian survey and reconnaissance of several hundred acres in the Upper Belize River Valley.

- Identified, documented and collected artifacts at several new Maya sites, including significant monumental complexes.

- Instructed field school students in introductory topics in Maya archaeology, settlement survey, and archaeological methods. 
Relevant Skills

Interests
Wilderness orienteering; Phase I, Phase II cultural resource survey; artifact identification and recovery; in-field mapping and site documentation; technical and academic report writing; GPS use and data management; planning and conducting fieldwork; basic GIS skills in archaeological applications.

Behavioral ecology, settlement dynamics and land-use patterns, huntergatherers, zooarchaeology, panarchy and landscape theory, geomorphology and site formation processes, sustainability, Marxism, archaeological applications of GIS.

- (December 2013) Phase I Archaeological Survey of the Proposed Swamp Road Mitigation Bank \#2, Rutherford County, Tennessee

- (October 2013) Transforming Campus Life Through Successful Transportation Alternatives. Christopher M. Sims and Andrea S. Zorn, presenters. Symposium presentation. Eco-Reps Campus Sustainability Week Presentations, Sustainable Transportation. Louisville, KY.

- (October 2013) Garden With Neighbors: Louisville's Potential to Promote Food Security Through Community Gardening. Shelly A. Biesel and Christopher M. Sims, presenters. Symposium presentation. CUMU Annual Conference, 2013. Louisville, KY.

- (October 2013) Transforming Campus Life Through Successful Transportation Alternatives. Dr. Justin Mog and Christopher M. Sims, presenters. Symposium presentation. AASHE Annual Conference, 2013. Nashville, TN.

- (October 2013) Garden With Neighbors: Louisville's Potential to Promote Food Security Through Community Gardening. Shelly A. Biesel and Christopher M. Sims, presenters. Symposium presentation. AASHE Annual Conference, 2013. Nashville, TN.

- (January 2013) Biesel, Shelly A. and Christopher M. Sims Garden With Neighbors: Louisville's Potential to Promote Food Security Through Community Gardening. Sustain: A Journal of Environmental and Sustainability Issues. 27: 39-48.

- (September, 2010) Phase I Survey and Phase I Intensive Investigations During Archaeological and Historic Evaluations of Nine Sites and Five Isolates at US Army Installation Fort Knox, Hardin, Meade, and Bullitt Counties, Kentucky

- (July, 2010) Archaeology Survey at the Paducah Sports Plex, McCracken County, Kentucky

- (April, 2010) Phase I Archaeological Investigations for the Proposed Cove Branch Wireless Communications Tower in Mt. Vernon, Rockcastle County, Kentucky

- (March, 2010) Phase I Archaeological Survey of a Proposed Coal Mine Operation for Southbound Coal, LLC. Near the Community of Burke in Elliott County, Kentucky 
- (March, 2010) Cultural Resource Investigations of the Proposed Dry Branch Surface Mine, McDowell County, West Virginia

- (March, 2010) Phase I Archaeological Survey for the Proposed Puncheoncamp Surface Mine, McDowell County, West Virginia

- (January, 2010) Section 106 Survey Results: A Phase I Archaeological Survey for the Proposed Winchester Municipal Utilities Sewage Trunkline Extension at Lower Howards Creek, Winchester, Clark County, Kentucky. 